\title{
Swiss Climate Change and Nuclear Policy: A Comparative Analysis Using an Energy System Approach and a Sectoral Electricity Model
}

\author{
Nicolas Weidmann ${ }^{a}$, Ramachandran Kannan ${ }^{a}$, and Hal Turton ${ }^{a}$
}

JEL-Classification: Q40, Q41, Q42, Q49, Q54, Q56

Keywords: MARKAL energy system model, TIMES electricity model, Swiss climate policy, Scenario analysis

\section{Introduction}

A number of factors are likely to affect the future configuration of the Swiss energy system. Besides the development of global energy prices, decisions on climate change mitigation policies and the future role of nuclear will have an important impact. However, there exists significant uncertainty about exactly how such policies may affect the development of the energy system. For instance, after the recent decisions of the Swiss Parliament to phase out nuclear energy (BFE, 2011a), it remains unclear as to which alternative generation technologies will be most suitable. Options under discussion include gas combined-cycle or combined heat and power (CHP) generation plants, and an accelerated deployment of renewables, but there remain significant technical, economic, environmental and political uncertainties about the suitability of these options. It is also unclear as to the extent to which efficient end-use technologies (e.g. heat pumps) and energy saving measures (e.g. building insulation) could contribute. Moreover, any possible transition away from nuclear energy needs to be consistent with Switzerland's objectives regarding the mitigation of climate change to avoid serious damages to natural and human systems, including agriculture, health, and

a Energy Economics Group, Laboratory for Energy Systems Analysis, Paul Scherrer Institut, 5232 Villigen PSI, Switzerland.

The authors would like to thank the reviewers and the editors for their valuable and most appreciated inputs and comments that supported the completion of this work. The results along with any errors or omissions remain solely the responsibility of the authors.

The support of NCCR Climate and the Swiss National Science Foundation is gratefully acknowledged. 
infrastructure. This likely requires the pursuit of relatively ambitious mitigation targets, such as those recommended by the Advisory Body on Climate Change (OcCC, 2007).

To understand more about the options for the long-term development of the Swiss energy system in the context of climate policy and uncertainty related to new nuclear investments, we analyse a number of scenarios. These what-if descriptions of the future help to identify robust trends and technology options that may be attractive for realizing a sustainable energy system, and thus help to inform decision makers. These scenarios are analysed with the Swiss MARKAL model (SMM), a least-cost optimisation model with a bottom-up depiction of the entire Swiss energy system. This model provides a detailed representation of energy supply and end-use technologies, including energy efficiency options. For this paper, we present scenarios reflecting stringent climate policy (OcCC, 2007) with two levels of support for nuclear power.

While SMM covers the full energy system, there are some features of the electricity sector in Switzerland that the model is unable to fully represent, and which could affect the suitability of different technology options for the development of the energy system. These include large variations in the electricity load and supply curve at different times of the day, and in different seasons. In SMM, this variation is represented in aggregate, by dividing the annual load curve into six different sub-periods (or "timeslices"). Thus, we couple SMM with an experimental TIMES (The Integrated MARKAL EFOM System) model of the Swiss electricity sector to provide complementary insights (KANNAN and TURTON, 2011). This Swiss TIMES electricity model (ST model) has an hourly electric load curve for several representative seasons and days, over a long time horizon.

The objective of this work is to show how a climate target can be met under different levels of support for future nuclear electricity generation and how the Swiss energy system is influenced. The results of this work are intended to support decision making on energy-related issues by identifying some of the options for achieving policy objectives, some of the trade-offs between different objectives, and the technologies that may be important for realising a sustainable Swiss energy system. Section 2 provides an overview of the two modelling tools and their key assumptions. Section 3 describes three scenarios that are analyzed in the paper. The results from the modelling analysis of these scenarios are then presented in Sections 4 and 5. Section 6 compares the results of the two modelling approaches, while Section 6 discusses some of the policy insights from this analysis. In Section 6, our analytical results are compared with the Swiss Energy Strategy 2050 (BFE, 2011b). Section 6 draws key conclusions and an outlook for future model development. 


\section{Methodology and Modelling Framework}

The analysis of the Swiss energy system is conducted using two complementary modelling approaches.

\subsection{Swiss MARKAL Model}

The Swiss MARKAL model (SMM) is a bottom-up energy system model depicting the entire Swiss energy system. The model represents energy service demand from five end-use sectors, comprising the residential, services, industrial, transport and agricultural sectors. Primary energy supply, conversion to secondary energy commodities (e.g. heat, electricity and hydrogen), and end-use demand technologies are explicitly modelled. $\mathrm{CO}_{2}$ emissions from the combustion of fossil fuels are tracked at the level of resource consumption. The model identifies the least-cost combination of fuels and technologies to satisfy future energy service demands (e.g., space heating) by taking into account technical, policy and external constraints. Energy service demands are exogenous inputs to the model, along with a range of technical and cost details for different technology options for resource extraction, energy conversion, transmission and distribution, and end-use devices. Primary and final energy demands, and electricity demand and profile, are outputs of the model.

The model has a time horizon of 50 years (2000 until 2050), with key sectors calibrated to the year 2009 ( $\mathrm{BFE}, 2010 \mathrm{a} ; 2010 \mathrm{~b})$. All cost assumptions in the

model are in $\mathrm{USD}_{2000}$, but we present the cost results in $\mathrm{CHF}_{2010}{ }^{1}$. The model development was firstly initiated at the University of Geneva (LABRIET, 2003) and subsequently developed by the Paul Scherrer Institute (Schulz, 2007 for more detailed documentation). It has been further developed and updated since, and used for a number of analyses (e.g., Schulz et al., 2007; 2008; WeidmanN et al., 2009; ETS, 2009). For this analysis, recent estimates of key technology costs (PSI, 2010) and renewable resource potentials (Hirschberg et al., 2004; SATW, 2007) have been implemented. Some of the key assumptions are given in the following subsection.

1 An exchange rate of $1.35 \mathrm{CHF}_{2010}$ per $\mathrm{USD}_{2000}$ is used. 


\subsubsection{Key Assumptions}

a. Future energy service demands are adopted from Schulz (2007) and are based on GDP and population growth. ${ }^{2}$

b. The international crude oil price is assumed to increase to $116 \mathrm{USD}_{2000}$ by 2050 (IEA, 2009). The prices of several other energy carriers (e.g. gas) are pegged to the oil price. Key resource costs and renewable potentials assumed for this analysis are given in Table 2.

c. Technical and cost data of new and future technologies are assumed as in PSI (2010) (Table 1). For this analysis, coal-based ${ }^{3}$ and geothermal ${ }^{4}$ electricity generation, and carbon capture and storage $(\mathrm{CCS})^{5}$ are assumed to be unavailable in Switzerland.

$\mathrm{d}$. The model uses a discount rate of $3 \%$ that reflects the real long-term yield on confederation bonds plus a risk premium for energy sector investments (SNB, 2010).

e. For all renewable electricity generation technologies bounds are included to reflect Swiss resource potentials (Table 2). Future hydro potentials are adjusted for losses in outputs due to residual water flows and climate change (ETS, 2009). In SMM, we assume that these hydroelectric potentials (which comprise existing plants and some small expansions) are fully exploited.

f. The existing nuclear plants are assumed to retire 50 years after installation $(\mathrm{BFE}, 2011 \mathrm{a} ; 2011 \mathrm{~b})$. Thus, the first reactor at the Beznau is scheduled to retire in 2019 followed by the second Beznau reactor and the Muhleberg reactor in 2022. The Goesgen nuclear plant is scheduled to retire in 2029 followed by the Leibstadt nuclear plant in 2034.

2 Population growth is based on scenario A-Trend from the Swiss Federal Office of Statistics (BFS, 2001), in which the Swiss population increases from 7.2 million in 2000 to 7.4 million in 2030. Afterwards, the population experiences a slight decline reaching about 7.1 million in 2050 .

3 Coal based electricity generation technologies are not included in both models since it is not seen as a realistic option if Switzerland sticks on reaching its climate targets. If coal plants with carbon capture and storage were to be available in the future, this might be changed.

4 Geothermal plants are fully restricted in both models given their political and technical uncertainties resulted from the first geothermal plant in Basel (HärING et al., 2009).

5 CCS is not included due to uncertainties in deployment of CCS technology and most importantly the availability of $\mathrm{CO}_{2}$ storage sites in Switzerland. 


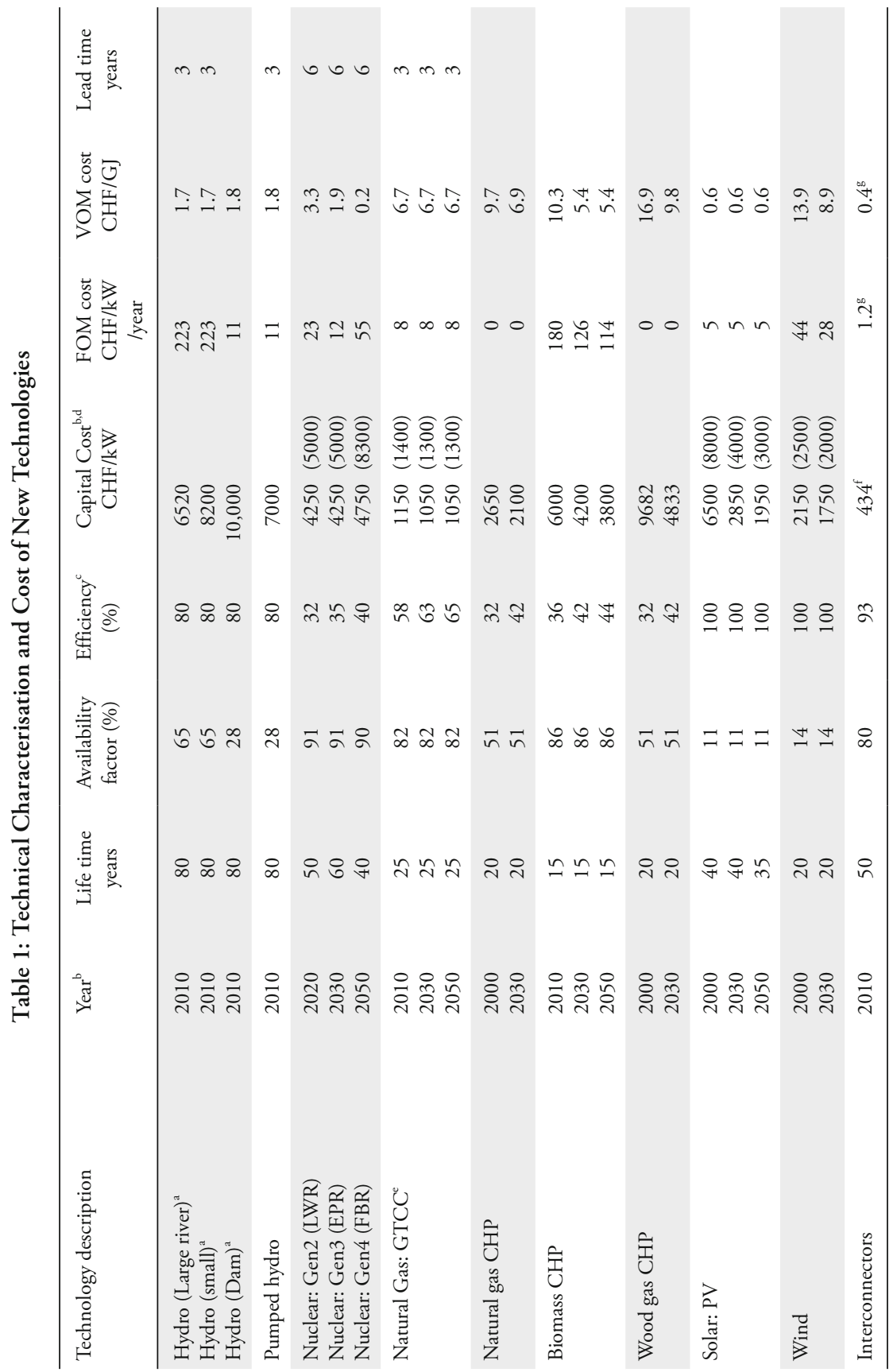

Swiss Journal of Economics and Statistics, 2012, Vol. 148 (2) 


\section{Notes to table 1:}

a All the existing hydro power plants can be refurbished after 80 years of their current operation from their construction period $(\mathrm{BFE}, 2004)$. The refurbishment cost is assumed to be one-third of the new build hydro plants.

b In the ST model technology cost and technical estimates are not interpolated between the vintage years. Instead, the old technology characteristics apply until the new vintage of technology becomes available.

c Its electrical efficiency. For CHP, heat efficiency of 40-54\% has been used.

d High cost assumptions are given in parenthesis.

e These are Base load plants. For flexible (merit order) plants, we used same cost assumption, but efficiency and availability factor are reduced by $20 \%$.

f Based on Air cable interconnectors @ 300 Euro/kW (Odenberger and Unger, 2010)

g Based on Swiss Grid (2009) network usage charges

\section{Table 2: Energy Resource Potential and Costs}

\begin{tabular}{|c|c|c|}
\hline Energy resources & $\begin{array}{l}\text { Costs } 2010-2050^{\mathrm{a}} \\
\left(\mathrm{CHF}_{2010} / \mathrm{PJ}\right)\end{array}$ & $\begin{array}{l}\text { Resource potentials } \\
(\mathrm{PJ} / \text { year })\end{array}$ \\
\hline Natural gas & 11.46-18.62 (PSI, 2010) & \\
\hline Uranium & $\begin{array}{l}0.38 \text { (PSI, 2010) } \\
0.64 \text { (for FBR) (PSI, 2010) }\end{array}$ & 94 PJ (Maintained at 2010 level) \\
\hline $\begin{array}{l}\text { Electricity import } \\
\text { (only in ST model) }\end{array}$ & 35.14-52.32 (ADAM, 2010) & $\begin{array}{l}\text { Max trade volume } 250 \mathrm{PJ}_{\mathrm{e}} \\
15 \mathrm{GW}(2050) / 21 \mathrm{GW}(2100) \\
\text { For export, } 20 \mathrm{GW}(2050) / 26 \mathrm{GW} \\
(2100)^{\mathrm{b}}\end{array}$ \\
\hline Wastes, biogas ${ }^{\mathrm{c}}$ & & $48 \mathrm{PJ}$ or $5 \mathrm{PJ}_{\mathrm{e}}$ (Maintained at 2008 level) \\
\hline Biomass $^{\mathrm{d}}$ & 9.7-7.10 (PSI, 2010) & $\begin{array}{l}76 \mathrm{PJ}_{\mathrm{t}}(2010) \\
98 \mathrm{PJ}_{\mathrm{t}}(2040)(\text { HirschBerg et al., 2004) }\end{array}$ \\
\hline \multirow[t]{2}{*}{ Hydro } & Existing & $\begin{array}{l}128 \mathrm{PJ}_{\mathrm{e}}(2010) / \\
114 \mathrm{PJ}_{\mathrm{e}}(2050)(\mathrm{ETS}, 2009)\end{array}$ \\
\hline & New & $\begin{array}{l}\text { 8.6 } \mathrm{PJ}_{\mathrm{e}}(2015) / 15.8 \mathrm{PJ}_{\mathrm{e}}(2050) \\
(\mathrm{BFE}, 2004 ; \mathrm{ETS}, 2009)\end{array}$ \\
\hline Solar PV & & $50 \mathrm{PJ}_{\mathrm{e}}(14 \mathrm{GW})$ (Hirschberg et al., 2004) \\
\hline Wind & & $14.4 \mathrm{PJ}_{\mathrm{e}}(2050)(\mathrm{ETS}, 2009)$ \\
\hline
\end{tabular}

a In the ST model, cost data for 2100 is assumed from the 2050 cost with an annual cost escalation of $1 \%$.

b Expert judgment (about 25\% higher than historical average level)

c Biogas is assumed to be from waste

d In the ST model, electricity generation from biomass is also bound to $3.8 \mathrm{TWh}$ as per SATW (2007) to limit the availability of biomass resources to the electricity sector. 


\subsection{Swiss TIMES Electricity Model (ST)}

The TIMES modelling framework is a successor to MARKAL, and has many of the same features. In addition, TIMES is able to model electricity load curves in more detail and has an enhanced energy storage algorithm, among other features (Loulou et al., 2005). The Swiss TIMES electricity Model (ST) is a single-region model, covering the Swiss electricity system from resource supply to electricity demand (in contrast, SMM covers the entire Swiss energy system). Primary energy resources in the model comprise renewable and imported fuels, which are used by the electricity generation technologies. Details of the energy resources and cost assumptions are the same as in SMM (Table 2). Demand for electricity ${ }^{6}$ is an exogenous input calculated by SMM (Figure 6). Figure 1 shows the coupling of the SMM and ST models.

The ST model has a time horizon slightly longer than a century (2000-2110) in 14 unequal time periods. Importantly, the ST model represents an hourly diurnal electric load curve (vs. day and night in SMM). All cost data are defined in 2010 Swiss francs $\left(\mathrm{CHF}_{2010}\right)$ and, as in SMM, a discount rate of 3\% is used. The model is fully calibrated between the years 2000 and 2009 to the historical data for electricity supply, demand, generation mix, trade and capital stock (BFE, 2010a; 2010b). All existing technologies in the Swiss electricity system have been included at an individual plant level or as a group aggregated by fuel and technology (for smaller plants). Capacity factors for all existing technologies have been calculated for the past 10 years $(\mathrm{BFE}, 2010 \mathrm{~b})$ and their statistical average is applied as the availability factor (of the existing technology) for future years. For existing technologies, operation and maintenance (O\&M) costs are accounted for using the same values as applied for the future technologies (Table 1). Unlike SMM, for all the large-scale power plants, construction time is included to account for lead times and interest costs incurred during construction. For other input assumptions (e.g., renewable potentials and cost), the ST model generally uses the same assumptions as SMM (Table 2).

As mentioned, the capabilities of the ST model enable a more detailed representation of the electricity load curve, including the large variations in electricity demand in Switzerland over the day and across seasons. This enables us to

6 There is no heat demand in the ST model even though combined heat and power generation technologies (CHP) have also been considered as a major technology (BFE, 2001) to replace oil and gas driven heat supply sources. In order to cope with operation of combined heat and power generation technologies CHP, heat output from CHP is currently modelled to be exported with small price incentive. 


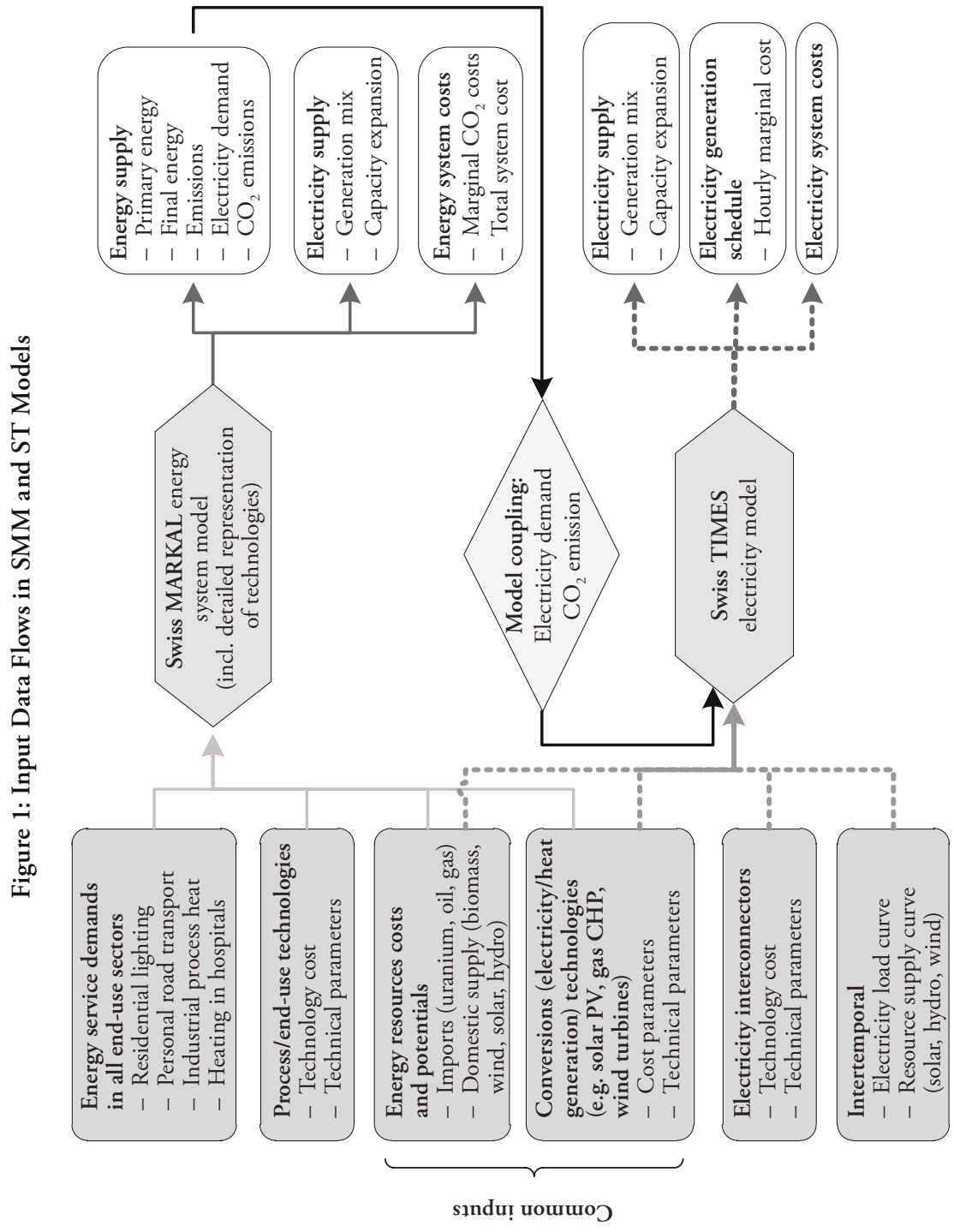


analyse operating characteristics of power plants in more detail. For example, all existing nuclear reactors are modelled as base-load plants, whereas large river and small hydro plants are characterised as seasonal base-load plants, with historical seasonal availability factors applied. Dam- and pumped-hydro plants are characterised as flexible (i.e. dispatchable or merit order) technologies. In addition to existing thermal and renewable electricity generation, the model has options to build base-load as well as flexible (dispatchable) combined-cycle gas power plants. These flexible plants are assumed to be $15-20 \%$ less efficient than the base load plants (i.e. 9-12 percentage points) to reflect the more erratic operational conditions. For solar PV, the availability factor is implemented at the hourly level based on average solar irradiation in Switzerland (JRC, 2009). Wind turbines are characterised as seasonal base-load plant and availability factors are implemented based on the monthly wind speed (WInD-DATA.CH, 2010). All other plants (e.g. $\mathrm{CHP}$ and waste incineration) are characterised as seasonal base-load plants. A capacity reserve margin of $30 \%$ is assumed; and intermittent renewable technologies like solar PV and wind are not included in the reserve calculation. An aggregated transmission and distribution (T\&D) loss of 7\% is assumed throughout the model horizon ( $\mathrm{BFE}, 2010 \mathrm{~b})$. The model also has a range of user-defined constraints to reflect historical operational patterns, technical and resources availability, market share, and so on. A full description and documentation of the model can be found in Kannan and Turton (2011).

Even though the ST model is a single region model, it includes a simplified representation of international electricity trade from the four neighbouring markets. Prices for electricity imports and exports are estimated based on electricity demand curves for the four surrounding countries (ENTSOE, 2010). We impose a self-sufficiency constraint from 2015 so that the annual net electricity trade is roughly in balance. The timing of electricity trade is left unconstrained, but annual exports and imports are required to be in balance, as in SMM.

Electricity demand is an exogenous input to the model. For the selected three scenarios (see Section 3) electricity demand between 2010 and 2050 is taken from SMM (Figure 6). Figure 1 shows the model inputs to ST and SMM and how the outputs from SMM are linked to the ST model. Demand between 2050 and 2100 is extrapolated with an annual growth of $0.27 \%{ }^{7}$. Future electricity demand is assumed to follow the 2008 Swiss national load curve (ENTSOE, 2010).

7 It is based on electricity growth between 2030 and 2035 in the Scenario - I of the Energy Perspectives (BFE, 2007). 


\subsection{Limitations of SMM and the ST model}

Like any analytical tool used to model complex systems, there are limitations in the MARKAL and TIMES frameworks. Sensitivity and scenario analysis are ways to address some of these uncertainties. The following should be borne in mind when considering the results:

- Future cost reductions for technologies (Table 1) are highly uncertain and depend on assumed technology development. Since both models rely on costminimization, different assumption on technology development, including unexpected breakthroughs, the emergence of new technologies, or slower improvements in existing technologies could change the picture significantly.

- The models assume perfect information, well-functioning markets and economically rational decisions, and are thus less suited to simulating technology choice in cases where there is significant market failure.

- Both models represent only Switzerland, whereas external developments will have a strong influence on the options available to Switzerland. For example, electricity trade is represented in a stylized way in SMM and the ST model, since surrounding markets are not represented. The applied methodology and assumptions may oversimplify a complex system, and ignore some of the factors affecting the availability of imports. The influence of some of these external developments is explored in Marcucci and Turton (2012).

\section{Scenario Definitions}

To understand future options for achieving a sustainable energy system in Switzerland, we analyze three scenarios considering climate change mitigation policy under two variants of nuclear policy (i.e. with and without replacement of existing nuclear capacity). In all scenarios we assume that Swiss policymakers and society continue to maintaining self-sufficiency in electricity production on average over the year.

\subsection{Reference Scenario (Ref)}

This is a business-as-usual scenario incorporating a limited number of policies in the calibrated model. For example, the current level of electricity generation from nuclear is assumed to be maintained during the entire time horizon, while hydro is assumed to be deployed up to the available potential adjusted for residual 
water flows and climate change (also see Section 2.1.1 (e)). It is also assumed that coal (see note 3), and geothermal (see note 4) electricity generation technologies and CCS (see note 5) are not deployed in Switzerland.

\subsection{Climate Scenario (CS)}

The climate scenario uses the same assumptions as the Reference scenario, but also includes a climate policy in which domestic $\mathrm{CO}_{2}$ emissions are reduced by $20 \%$ by 2020 , and by $60 \%$ by 2050 relative to the year $1990 .^{8}$ These emission targets are similar to the recommendation of the Swiss Academies of Arts and Sciences (SAAS, 2009) and the Advisory Body on Climate Change (OcCC, 2007). These emission targets are implemented to the Refscenario as cap on total emissions across the entire energy system in SMM. In the ST model, a cap is placed on electricity sector emissions corresponding to the electricity sector emissions in SMM. Thus, the models determine which abatement options to deploy, based on the cost of different technology options across all sectors ('how' flexibility). Like in the Refscenario, the level of nuclear investment is maintained at today's level.

\subsection{Climate Scenario without New Nuclear (CS_N)}

For this scenario we assume the same climate change mitigation target as in the $C S$ scenario. In addition, we assume that existing nuclear capacities are not replaced after the end of their 50-year lifetimes (see Section 2.1.1 (f)). This scenario is roughly in line with the policy recently announced by the Swiss Parliament (BFE, 2011a).

\section{Energy System Results from SMM}

\subsection{Reference Scenario}

In the Refscenario total primary energy consumption remains more or less constant over the entire time horizon, as shown in Figure 2. Hydro and nuclear energy maintain their contribution to total primary energy, as per the assumptions applied for the deployment of these technologies (see Section 2.1.1 (e) \&

8 Since international aviation and shipping demands are included in the model, the emission constraints are adjusted to exclude the $\mathrm{CO}_{2}$ emissions associated with the fuel use for these end-use demands. 
Section 3.1). By 2035, gas demand doubles as it replaces oil use in the transport and residential sectors, and is also used in electricity generation. By 2050, natural gas is replaced by solar energy - mainly for electricity generation via solar PV. The share of biomass in primary energy stays roughly constant over the time horizon.

Figure 2: Primary Energy Supply in SMM

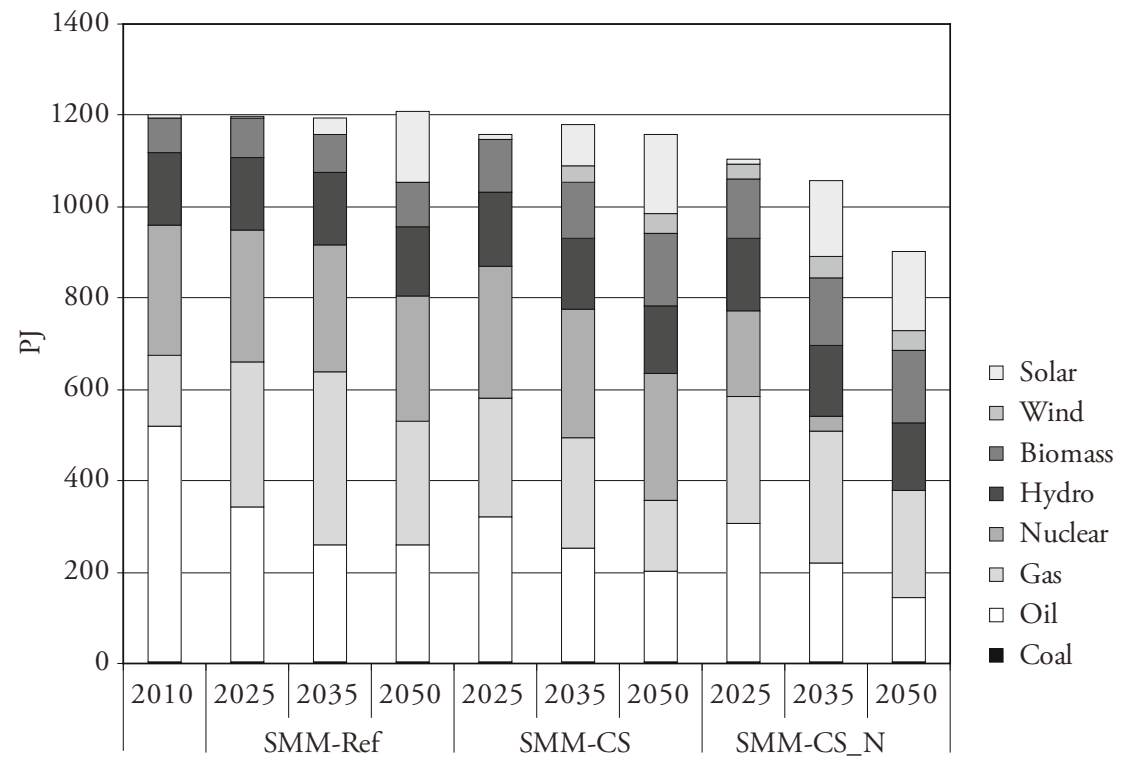

Final energy consumption gradually decreases ${ }^{9}$ over the time horizon (Figure 3 ) mainly in the residential sector resulting from deployment of some energy-saving options in space heating and a shift to more efficient heating technologies (see the discussion below). There are only smaller changes in final energy consumption across the other end-use sectors in this Ref scenario (Figure 3) (e.g. industrial energy demand decreases due to efficiency improvements, while the service sector's energy demand increases partially due to an assumed increasing use of commercial office equipment (Figure 3a)).

9 The decrease in final energy consumption, while primary energy remains more or less constant, can be partly attributed to the nominally lower efficiency assumed for solar electricity generation (since a fossil-equivalent efficiency is assumed for solar PV for the calculation of primary energy). 
Figure 3: Final Energy Consumption by End-Use Sector and Fuel Type
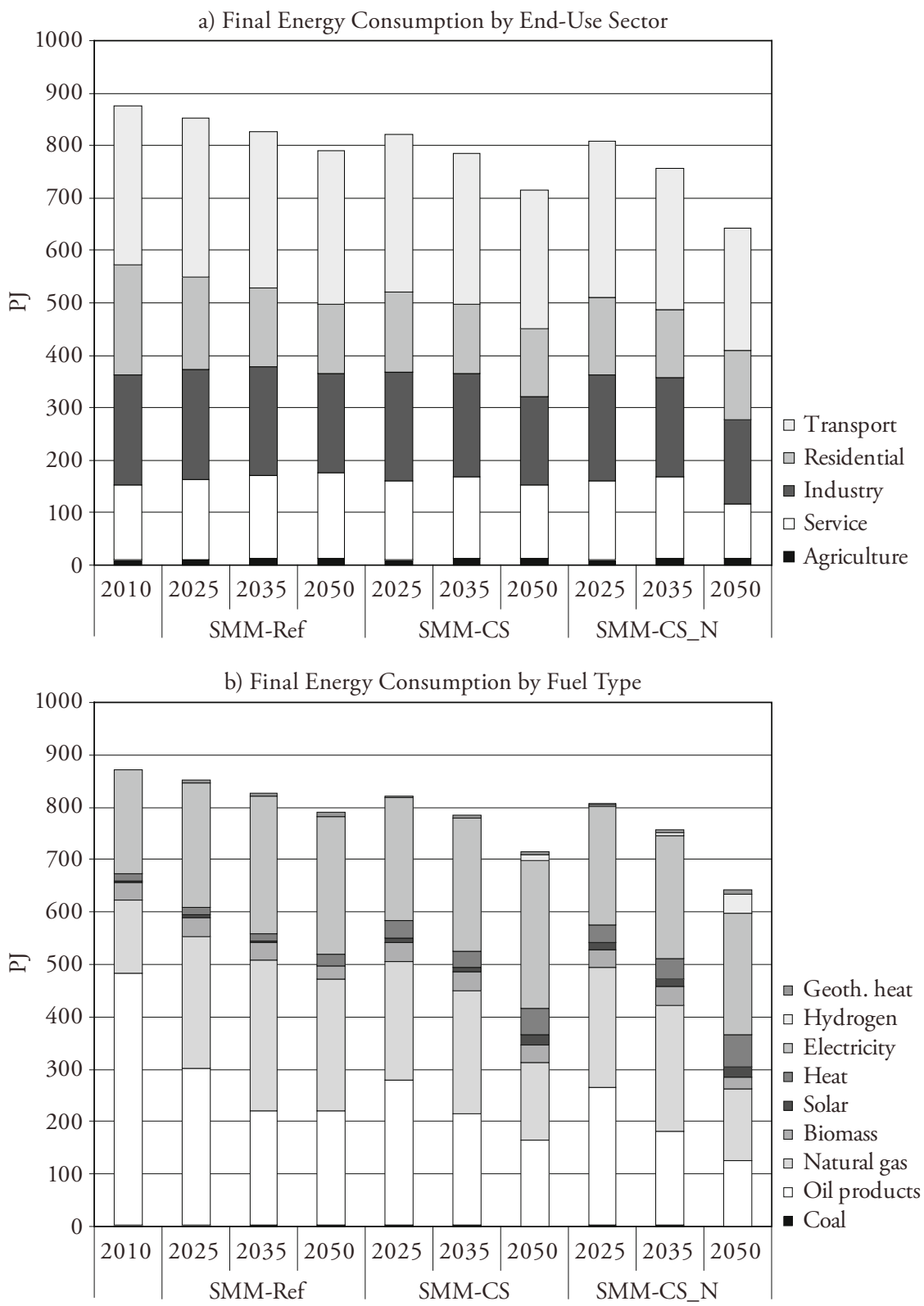
The reduction of final energy consumption in the residential sector is realised from investments in energy-saving measures such as insulation and energyefficient appliances such as lighting, dishwashers, etc. The residential final energy mix (Figure 4) shows that there is fuel switching in heating from oil to natural gas and electricity used in heat pumps. In 2050, natural gas is further replaced by electricity due to the increasing price of gas.

Figure 4: Final Energy Consumption in Residential Sector

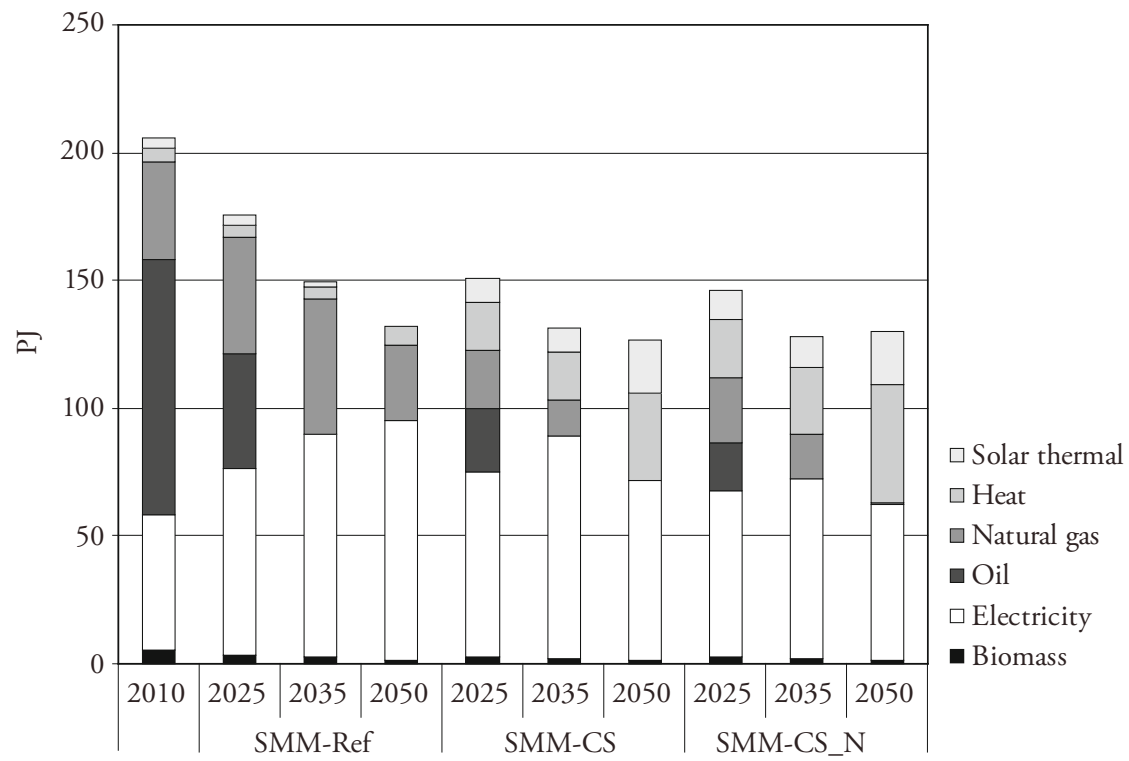

As can be seen in Figure 3a, transport sector final energy consumption declines over the time horizon. This is partially due to investments in efficient vehicle technologies (Figure 5). In addition, there is a shift from gasoline to diesel and natural gas in the car sector; and from diesel to gas in the truck fleet. There is no significant change in rail or aviation fuel demands because of limited alternative technology options assumed in the model. 
Figure 5: Final Energy Consumption in Transport Sector

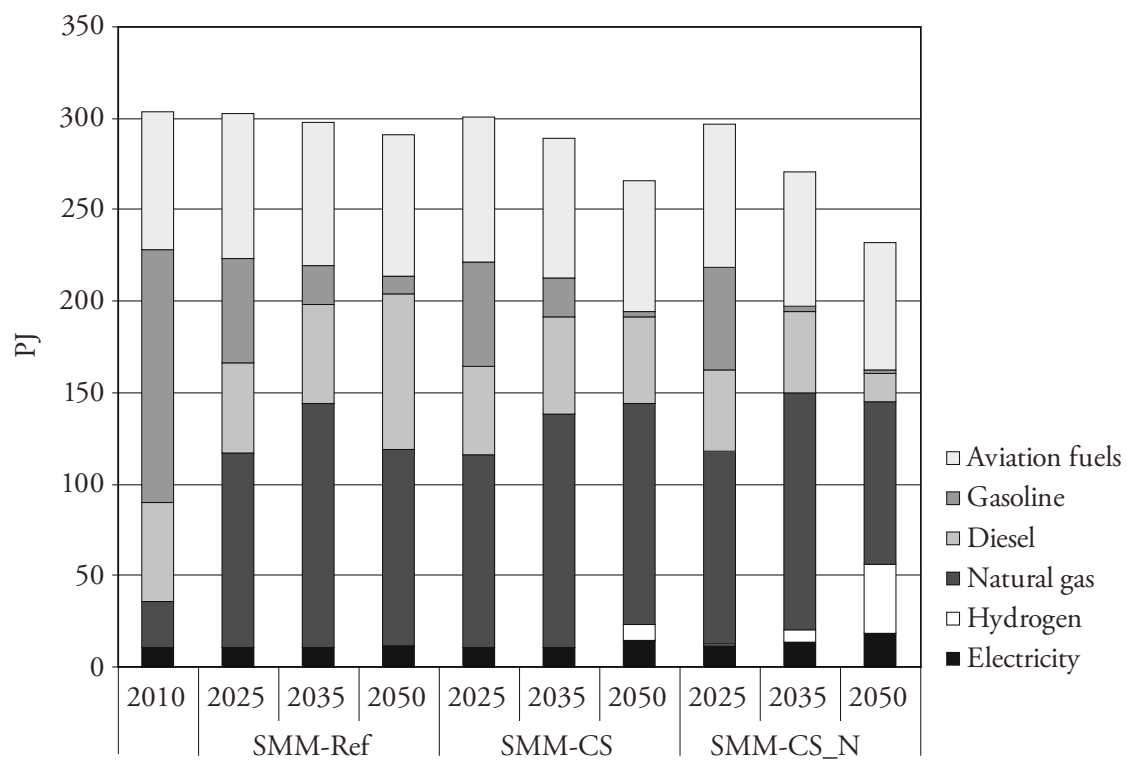

From today's level, electricity demand (Figure 3b) increases and peaks between 2035 and 2040 mainly because the residential and service sectors switch partly to electric heating with heat pumps and resistance heaters (Figure 4). In subsequent periods, electricity demand declines as the service heating sector switches back from electricity (used in resistance heaters) to natural gas. This occurs despite natural gas becoming more expensive, because electricity costs are also increasing (partly because gas is also used extensively in electricity generation, see below) (Figure 6).

On the supply side, electricity is produced mainly from hydro and nuclear power (Figure 6). As electricity demand increases and nuclear and hydro capacities are used to their full potentials, the additional demand is supplied by gas combined-cycle plants. Between 2035 and 2050 the model shifts from gas-based generation to solar PV due to assumed reductions in solar PV costs, while the gas price continues to increase. Although solar PV generation becomes competitive, it is still relatively expensive, and thus efficient end-use technologies (e.g. district heating) are deployed to reduce electricity demand. 
Figure 6: Electricity Generation from SMM

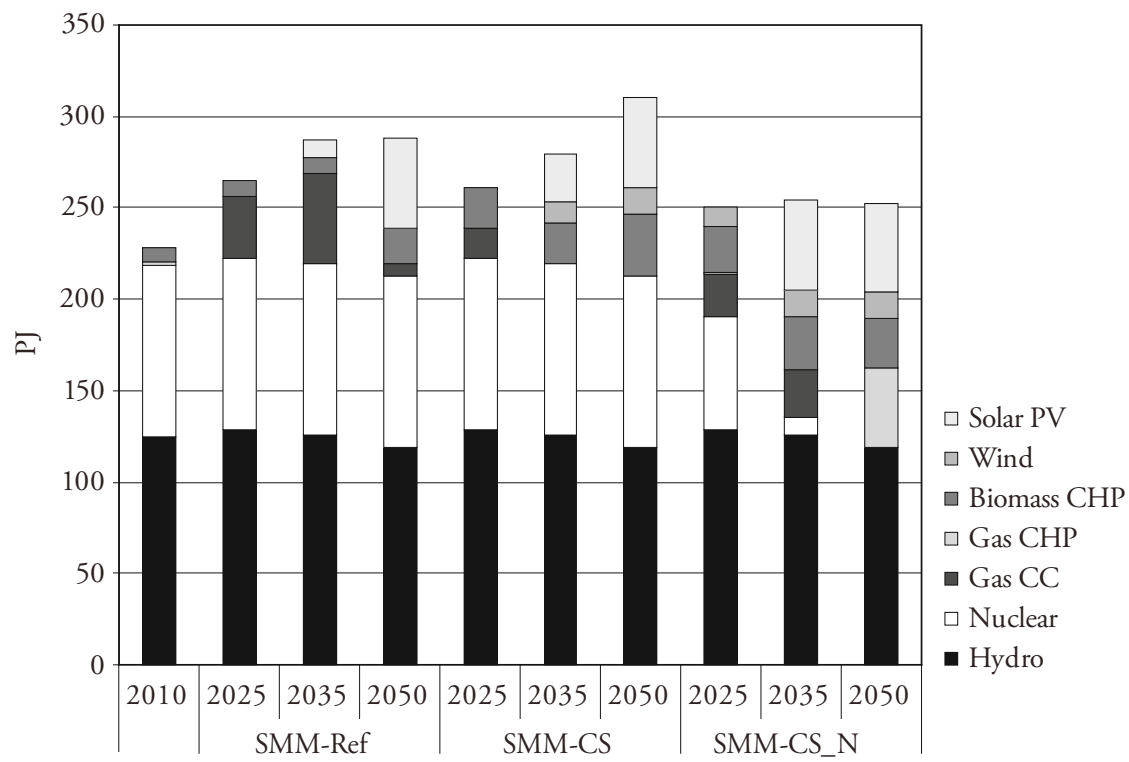

Total $\mathrm{CO}_{2}$ emissions in the energy system decrease by approximately $10 \%$ by 2020 and $30 \%$ by 2050 relative to the 1990 level mainly because heating oil use in the residential sector is reduced. Emissions from transport (representing the other main source of $\mathrm{CO}_{2}$ ) remain roughly stable because the effect of increasing demands for transport over the time horizon is offset by a switch to more efficient technologies and lower-emissions fuels (e.g. diesel to natural gas). The emissions from the industrial sector slightly decrease towards the end of the time horizon because of fuel switching (fossil fuels to electricity and biofuels) and increased efficiency. In the services sector there is a moderate decline in $\mathrm{CO}_{2}$ emissions between 2025 and 2040 due to a shift to electricity for heating (replacing emissions-intensive oil heating), but after 2040 there is a shift back to gas, as electricity becomes expensive. Emissions in the electricity sector reflect the generation mix. Initially, generation is almost $\mathrm{CO}_{2}$ free, but between 2025 and 2040 there is a large expansion of natural gas generation resulting in a high level of emissions. However, this expansion of electricity output helps to reduce emissions in the end-use sectors since electricity is used to replace oil for heating in the residential and services sectors. Towards the end of the time horizon, when solar PV is deployed on a relatively large scale, gas is partly replaced and, thus, emissions in the electricity sector also decrease (Figure 6). 
Figure 7: Sectoral $\mathrm{CO}_{2}$ Emissions from SMM

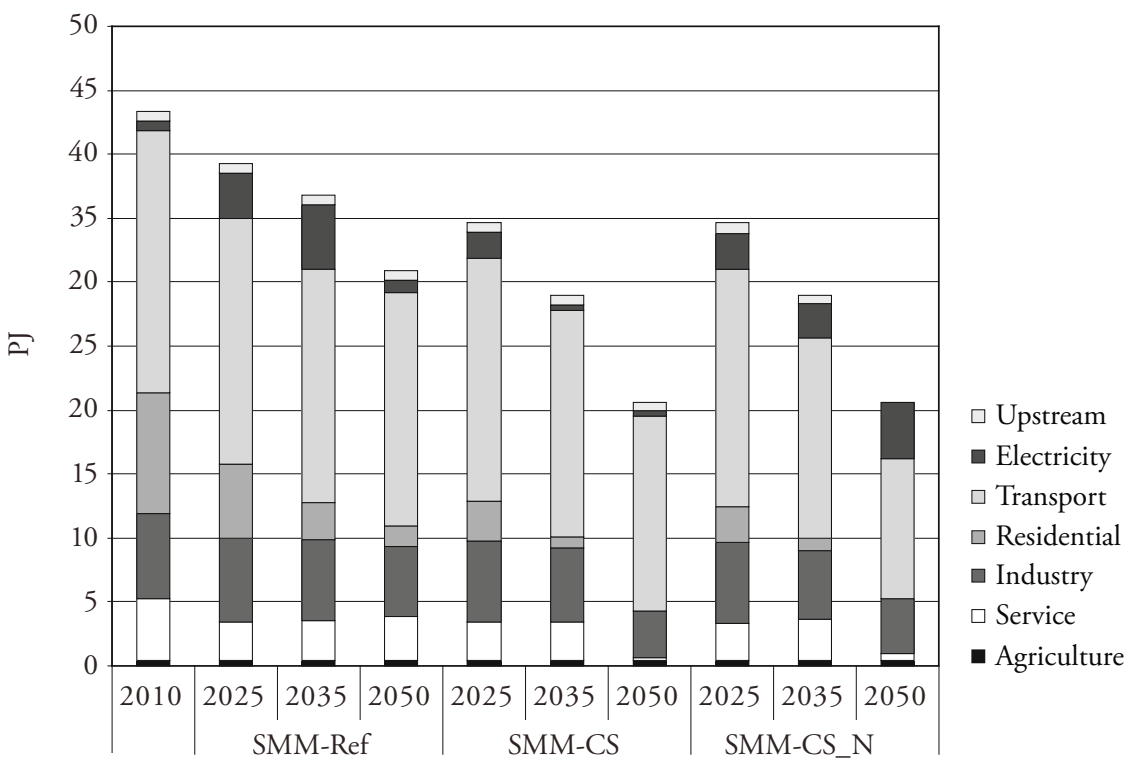

The cumulative undiscounted energy system cost in the Ref scenario over the next 40 years from 2010 to 2050 is about CHF 2260 billion, which is equivalent to about $9.6 \%$ of the GDP over the same time period (Table 3). In the following subsections, the cost of the climate policy scenarios is compared to these system costs in the Refscenario.

\subsection{Climate Scenario}

As noted above, in the Refscenario, $\mathrm{CO}_{2}$ emissions decline by only $10 \%$ by 2020 and $30 \%$ by 2050 relative to the 1990 level. This is not sufficient to realise longterm climate policy goals, and thus additional changes are required to the energy system. In the $C S$ scenario, we examine the energy system developments needed to realize a $20 \%$ reduction in 2020 and a $60 \%$ reduction by 2050 .

In the $C S$ scenario, primary energy demand declines marginally with respect to the Refscenario. As expected, to meet the $\mathrm{CO}_{2}$ abatement target there is a shift from fossil fuels - gas in particular - to renewables. This trend is more noticeable at the end of the time horizon when the climate target becomes most stringent. Besides the earlier deployment of solar PV for electricity generation, wind 
Table 3: Undiscounted Energy System Costs from SMM

\begin{tabular}{|c|c|c|c|}
\hline & Ref scenario & CS scenario & CS_N scenario \\
\hline & \multicolumn{3}{|c|}{ Billion $\mathrm{CHF}_{2010}$} \\
\hline $\begin{array}{l}\text { Cumulative }{ }^{a} \text { undiscounted energy system } \\
\text { cost }\end{array}$ & 2,260 & 2,275 & 2,459 \\
\hline Cumulative ${ }^{a}$ Swiss GDP (Schulz, 2007) & & 23,528 & \\
\hline $\begin{array}{l}\text { Incremental cost with respect to the Ref } \\
\text { scenario }\end{array}$ & - & 14.436 & 198.639 \\
\hline $\begin{array}{l}\text { Incremental cost with respect to the Ref } \\
\text { scenario [\%] }\end{array}$ & - & $0.64 \%$ & $8.79 \%$ \\
\hline $\begin{array}{l}\text { Incremental cost with respect to the GDP } \\
{[\%]}\end{array}$ & - & $0.06 \%$ & $0.84 \%$ \\
\hline
\end{tabular}

over 40 years time period (2010-2050)

turbines are also built in 2035. By 2050 the full potential of wind electricity is exploited. In comparison to the Ref scenario, biomass is used to a larger extent to replace carbon-intensive fossil fuels.

Final energy consumption is about 3-9\% lower than in the Ref scenario due to fuel and technology substitution (Figure 3). This is partly due to increased uptake of energy-saving and efficiency measures, and an increase in electrification (with electricity demand around $7 \%$ higher in 2050) in order to reduce the consumption of carbon-intensive fuels compared to the Refscenario. A shift to expensive low-carbon fuels also makes efficiency options more competitive. For example, energy saving measures become highly attractive in the residential sector. Similarly, energy demand in the transport sector also decreases at the end of the time horizon due to uptake of efficient vehicles (e.g. hybrid cars).

In the residential sector, an accelerated phase out of oil-based heating is seen (Figure 4). Initially there is also a shift towards electric heating, but over the longer term as the $\mathrm{CO}_{2}$ constraint becomes increasingly stringent, electricity generation becomes more expensive. Thus, unlike in the Refscenario the model chooses district heat and solar hot water systems for heating. By the end of the time horizon, the residential sector is almost fully decarbonised (Figure 7).

In the transport sector, there is a rapid shift from oil to natural gas (Figure 5). In addition, an increased uptake of efficient cars and trucks reduces both transport fuel demand (Figure 5) and emissions (Figure 7) in the transport sector. 
These developments are consistent with earlier analysis (SCEIA et al., 2009) which showed that stringent climate policy requires substantial changes to the car fleet in terms of fuel switching (from oil to natural gas) and uptake of efficient technologies (hybrid car). By the end of the model time horizon, hydrogen cars become attractive (with hydrogen produced from wood biomass, which is assumed to be carbon neutral). Also in domestic aviation some improvements in energy efficiency are taking place in order to meet the climate target.

To meet the climate target, the system reduces emissions mainly in the residential, service and industrial sectors in the second half of the model time horizon. In the transport sector, emissions are reduced only by $25 \%$, partly because there are limited cost-effective low-carbon alternatives. Compared to the Ref scenario, the emissions from the electricity sector are significantly reduced since gas combined-cycle generation is partly replaced by renewables (solar, wind and biomass) (Figure 6).

The cumulative undiscounted energy system cost of the $C S$ scenario is about CHF 2275 billion. The additional cost of the climate policy compared to the Ref scenario is about CHF 14.4 billion over the next 40 years or $0.06 \%$ of the cumulative GDP over the next 40 years (Table 3). This additional cost is attributable to large investments in capital-intensive $\mathrm{CO}_{2}$ abatement technologies (3-16\% higher capital investment than the Refscenario), which is only partly offset by reduced expenditure on fuels (e.g. gas) (up to $8 \%$ lower than the Refscenario). The marginal cost of $\mathrm{CO}_{2}$ varies between CHF 40 and CHF 2422 per ton of $\mathrm{CO}_{2}$.

\subsection{Climate Scenario without Nuclear}

In this scenario, the existing nuclear power plants are assumed not to be replaced after reaching the end of their 50-year operating lives. As a result, it is necessary to deploy alternative low-carbon energy sources, which are limited. This also makes efficiency measures very attractive at the supply and demand sides, reducing final energy demand (and hence primary energy demand) by up to 10\% between 2025 and 2050, compared to the $C S$ scenario (Figure 2). The stringent climate policy renders oil less attractive and therefore there is a slight increase in the share of gas between the CS and $C S \_N$ scenario in 2050 (i.e. as the model switches from oil to lower-emissions natural gas). At the end of the time horizon the renewable energy sources are exploited to their full potentials (Table 2).

Compared to the CS scenario, final energy consumption is reduced significantly in the services sector (up to $34 \%$ by 2050 ) and up to $20 \%$ in the transport and industrial sectors. The industrial sector deploys gas-based CHP which increases this sector's direct emissions. In the residential sector, final energy 
remains at approximately the same level as in the CS scenario, in which almost all efficiency options are already exploited.

Due to the nuclear phase-out, the energy system loses a relatively low-cost option of producing low-carbon electricity in the second half of the scenario time horizon, at the same time as the climate target becomes more stringent. Consequently, electricity prices are higher in this scenario and total electricity demand is reduced compared to both the Ref and CS scenarios. This is realised through additional energy saving measures and a reduced rate of electrification in some end-use sectors, such as in residential heating (replaced by district heat) compared to the CS scenario (Figure 4). This reduced use of electricity means additional abatement measures are required in end-use sectors to meet the mitigation target - for example, in transport more expensive efficient technologies and fuel-switching options (replacing some oil and gas with hydrogen and electricity) are exploited (Figure 5).

The electricity sector undergoes major changes in the $C S \_N$ scenario to cope with the phase-out of nuclear, particularly at the later periods. To meet the electricity demand at the end of the time horizon, gas combined cycle plants are deployed and all renewable potentials are fully exploited. The increased use of natural gas increases emissions in the electricity sector, requiring additional abatement in other sectors (particularly the transport sector as mentioned above).

Meeting the climate target without new investment in nuclear increases the cumulative undiscounted energy system costs by $8.8 \%$ compared to the Ref scenario. ${ }^{10}$ The incremental cost of the $C S \_N$ scenario is about $0.84 \%$ of GDP (vs. $0.06 \%$ in the CS scenario) (Table 3). However, the marginal price of $\mathrm{CO}_{2}$ remains relatively modest for much of the scenario time horizon $(<\mathrm{CHF} 150$ per ton), rising substantially only at the very end as the climate policy becomes increasingly stringent and the last nuclear plants are shut down (reaching above CHF 15,000 per ton in 2050) (Figure 11).

These scenarios for the Swiss energy system illustrate some of the possible implications of climate and nuclear policy. The systems approach in SMM shows the potential of different sectors and technologies to contribute to energy policy goals. We now turn to the results focusing on additional detail in the electricity sector derived from the ST model. As mentioned, the ST model uses the demand and emissions outputs of SMM as inputs for the electricity sector presented above (Figure 1).

10 The incremental cost of the $C S \_N$ scenario compared to a reference case with a nuclear phaseout (not analysed here) is likely to be larger than the cost difference between the CS scenario and the Refscenario, since nuclear generation is a relatively low-cost source of low-carbon electricity. 


\section{Results from the ST Model}

\subsection{Electricity Generation Mix}

In the Ref scenario, increasing electricity demand is met in the short term with new investment in $1.1 \mathrm{GW}$ of natural gas combined-cycle plants by 2025 , since this technology can be deployed rapidly. This technology contributes $12 \%$ of the total generation in 2025 (see Figure 8, which also reproduces SMM results), which results in $3.3 \mathrm{Mt} \mathrm{CO}_{2}$ emissions. In the medium and long run, nuclear is the most cost-effective option. The first new nuclear plant begins operation in 2025 , and nuclear contributes around $35 \%$ of total generation. Since nuclear electricity generation is maintained at today's level of $94 \mathrm{PJ}$ (Section 3.1), and thus restricted from expanding, the growing electricity demand is met with more gasbased generation. The share of gas generation reaches $18 \%$ by $2050^{11}$ (Figure 8 ) and emissions peak at $5.5 \mathrm{Mt} \mathrm{CO}_{2}$. As solar PV becomes increasingly competitive from 2050, a large investment in solar PV begins and the full potential is exploited by 2065. In the long run (by 2080), solar PV achieves a market share of $16 \%$ of the total generation while hydro, nuclear and gas contribute $43 \%, 31 \%$ and $6 \%$ of the electricity supply, respectively.

The generation mix in the $C S$ scenario is similar to the Refscenario, but some of the gas-based generation is replaced by wind $(1.1 \mathrm{GW})$ in 2025 due to the $\mathrm{CO}_{2}$ constraint. The wind generation is attractive because of its high availability during winter, when electricity demands are also high. Investment in solar PV also begins from 2035 (vs. 2060 in the Ref scenario) when slightly cheaper solar PV becomes available. By 2050, non-hydro renewables contributes to $26 \%$ of the total generation versus $4 \%$ in the Ref scenario (Figure $8 \mathrm{~b}$ ). In the long run (beyond 2050), electricity demand is assumed to continue to grow (see note 7). Because nuclear energy is maintained at today's level, and there are limited domestic renewable resources, it thus becomes impossible to maintain an almost zero-carbon electricity supply without net imports (which are thus allowed from 2050). It is worth noting that use of geothermal for electricity generation is excluded from the analysis (see note 4). Thus, up to $12 \%$ of the demand is met with imported electricity by 2080 .

In the CS_N scenario, electricity demand in 2050 is $18 \%$ lower than the CS scenario (see SMM results in Figure 6). Thus, although nuclear is phased out in this scenario, the lower demand means that much less generation needs to be

11 Years specified in the figures represent the mid-year of periods, i.e. 2020 represents 2018-22; 2048: 2041-55. 
replaced. Gas-based generation is also able to contribute more to replacing nuclear because the $\mathrm{CO}_{2}$ constraint in the $C S \_N$ scenario is also less stringent (about $1.8 \mathrm{Mt}$ ) than in the $C S$ scenario, because other sectors make a larger contribution to abatement (Figure 7). Gas generation contributes up to $11-18 \%$ of the total supply between 2025 and 2050. In the long run (through 2080) imported electricity again plays a vital role.

\subsection{Electricity Generation Schedule}

Electricity generation schedules from the three scenarios for the year 2050 (2048) on a summer weekday are shown in Figure 9. In the Ref scenario, supply from the base-load (nuclear, river hydro and gas) plants is adequate to meet demand (thick line in generation schedule plot in Figure 9) between midnight and $8 \mathrm{am}$. To meet demand in other timeslices, dam hydro and pumped hydro plants are also scheduled. Excess generation is exported during the daytime, when export prices are assumed to be high. In some timeslices (e.g. $8 \mathrm{pm}-3 \mathrm{am}$ ) both imports and export occurs, in order to exploit assumed price differences between the trading regions. At the same time, between 3 am and 5 am the imported electricity is stored via pumped hydro facilities, which is indicated with wavy shades in the export (lower) plot in Figure 9. Pumped storage is scheduled during daytime $(9 \mathrm{am}-4 \mathrm{pm})$ when export prices are high. The marginal cost of electricity in the Ref scenario varies between 11 and 15 Rappen per $\mathrm{kWh}(\mathrm{Rp} / \mathrm{kWh})$ on summer weekdays (and between 8 and $17 \mathrm{Rp} / \mathrm{kWh}$ over the year, including weekends).

Unlike in the Refscenario, base-load generation is not sufficient to meet the higher demand in the CS scenario during summer weekdays in 2050. At night time, demand is met with electricity imports. During the daytime, the additional generation from solar PV ensures that supply is sufficient to meet demand. Nevertheless, dam hydro is also scheduled during daytime hours, with the excess generation exported. ${ }^{12}$ Recalling the self-sufficiency constraint (Section 2.2), the high level of exports not only generates revenue, but enables imports of electricity during periods of high demand (namely in winter). The daytime electricity output from solar PV is favourable for supplying summer peak demand as well as the export market when prices are assumed to be high. The intermittence of

12 The dam hydro plants could be scheduled to meet night-time demand instead of using imported electricity. However, it is cost-effective to schedule the hydro plant during the daytime to generate export revenue when prices are high; and import cheap electricity to meet night-time demands. 
Figure 8: Electricity Generation Mix from ST and SMM Models
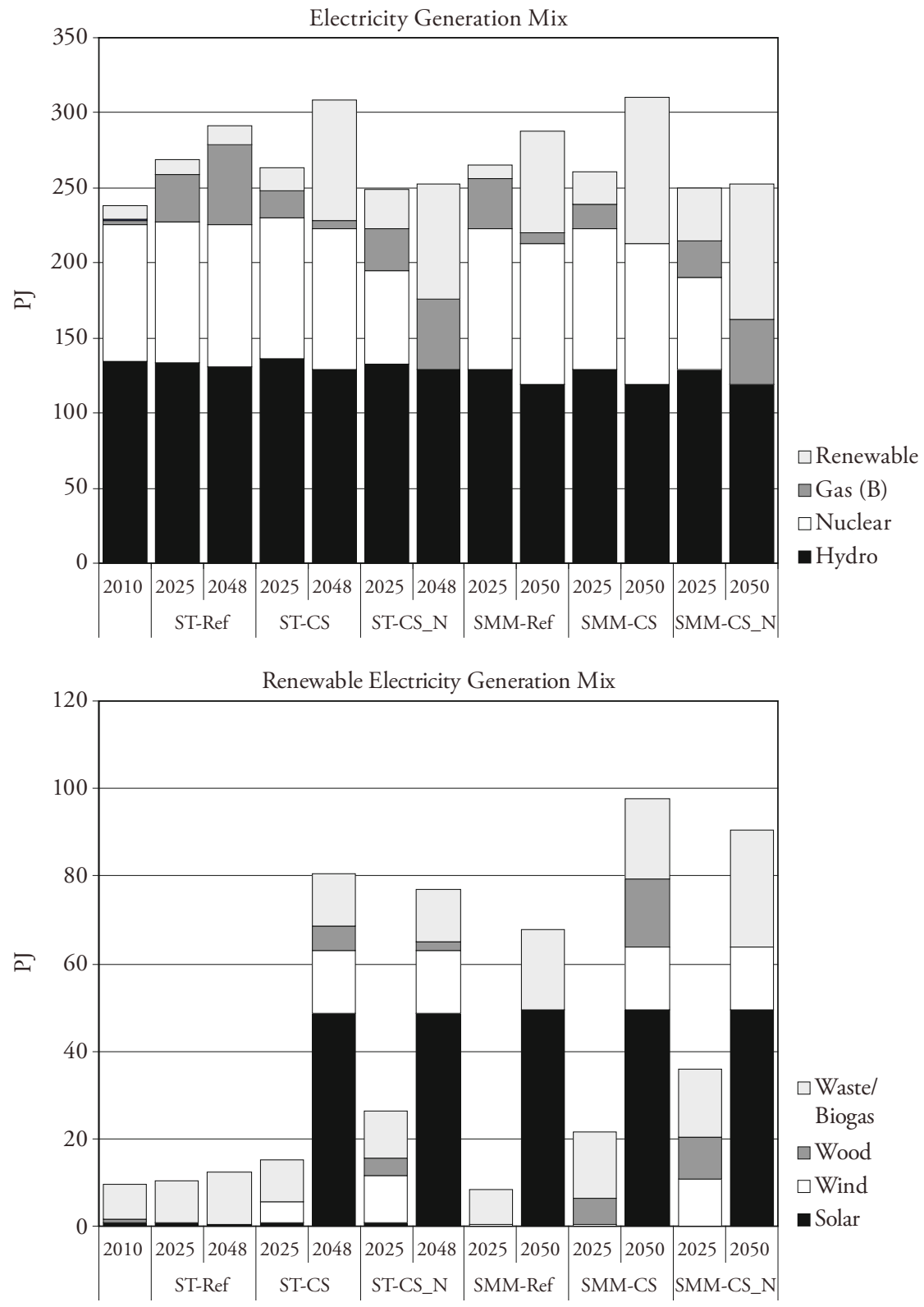
the solar PV generation could be managed with the large dam hydro facilities. The marginal cost of electricity in the CS scenario varies between 21 and 25 $\mathrm{Rp} / \mathrm{kWh}$ on summer weekdays (and between 18 and $28 \mathrm{Rp} / \mathrm{kWh}$ over the year).

The generation schedule for the $C S \_N$ scenario is similar to the $C S$ scenario. Despite the absence of nuclear capacity, the marginal cost is on par with the CS scenario because the demand is lower.

In contrast to the export-driven summer electricity system, winter demand is largely met with imported electricity. The generation schedule for a winter weekday is shown in Figure 10. In all the scenarios, the demand is far higher than the supply from base-load generation. The output from river hydro (and solar PV) is low in winter, while demand is substantially higher. Thus, the system relies heavily on imported electricity. The model optimises such that imports occur during periods of low prices (night time), with domestic supply scheduled during highprice periods (corresponding to the midday and evening peaks). Thus, in all scenarios, dam hydro is scheduled at these intervals. In all scenarios, the marginal cost of electricity is about 3-6 Rp/kWh higher in winter than in summer time. Again, as in summer, import and export occur simultaneously at some timeslices (e.g. $10 \mathrm{am}$ and $6 \mathrm{pm}$ ), which can be attributed to the assumed price differences in neighbouring countries.

\subsection{Cost Implications}

In terms of cost, annual undiscounted cost in the Refscenario in 2050 is about CHF 4.2 billion, including net revenue of CHF 370 million from electricity trade (Figure 11). The average cost of electricity is $5.6 \mathrm{Rp} / \mathrm{kWh}$ in the Ref scenario. However, marginal of electricity cost at an hourly level varies between 8 and 17 $\mathrm{Rp} / \mathrm{kWh}$. It is not possible to compare directly the additional cost of the climate or no nuclear policies from the ST model, because the electricity demands are not same between the scenarios. The average cost of electricity increases from $5.6 \mathrm{Rp} / \mathrm{kWh}$ in the Refscenario to $6.3 \mathrm{Rp} / \mathrm{kWh}$ and $8.1 \mathrm{Rp} / \mathrm{kWh}$ in the $C S$ and $C S \_N$ scenarios respectively. 

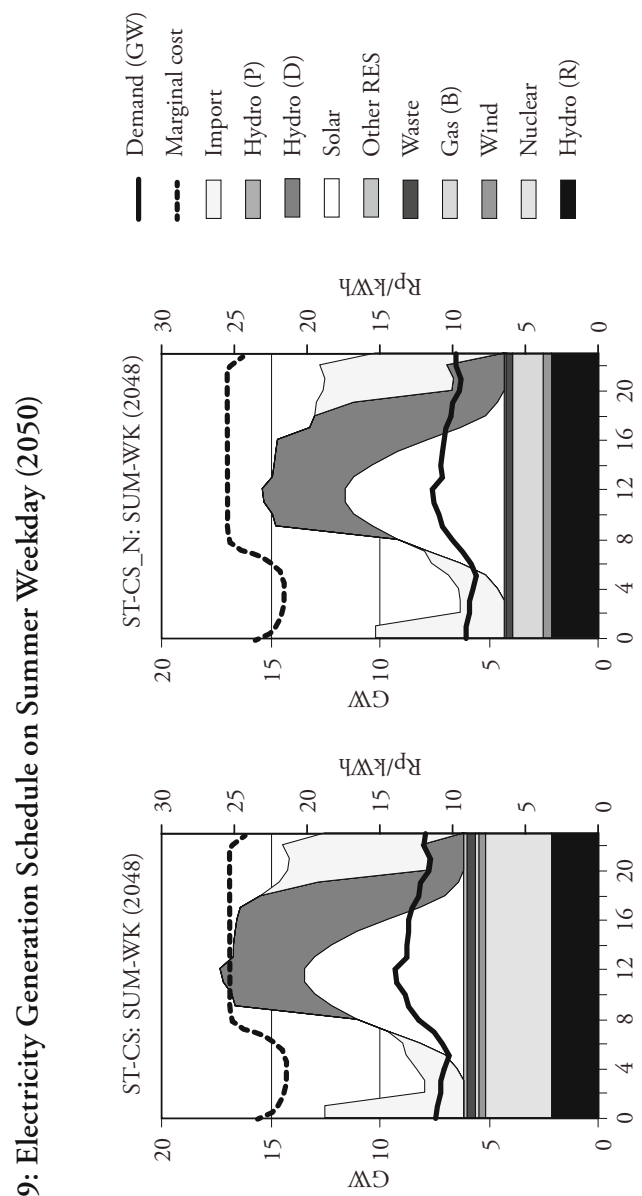

总

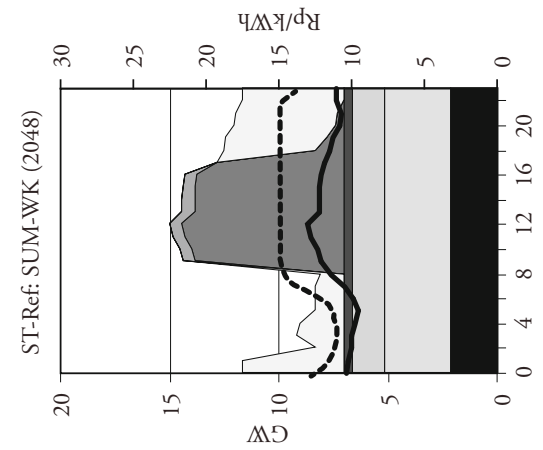

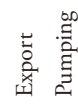
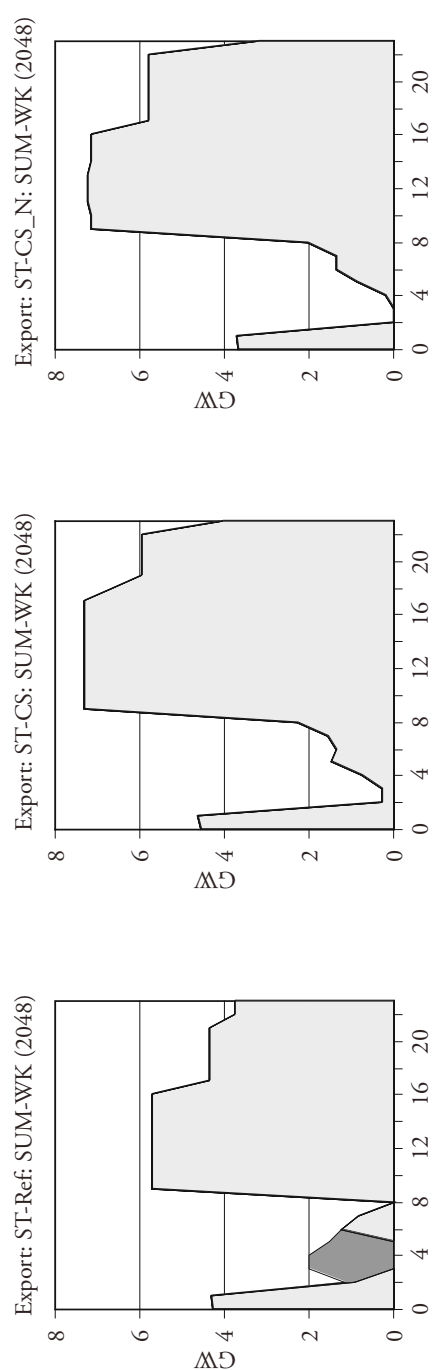

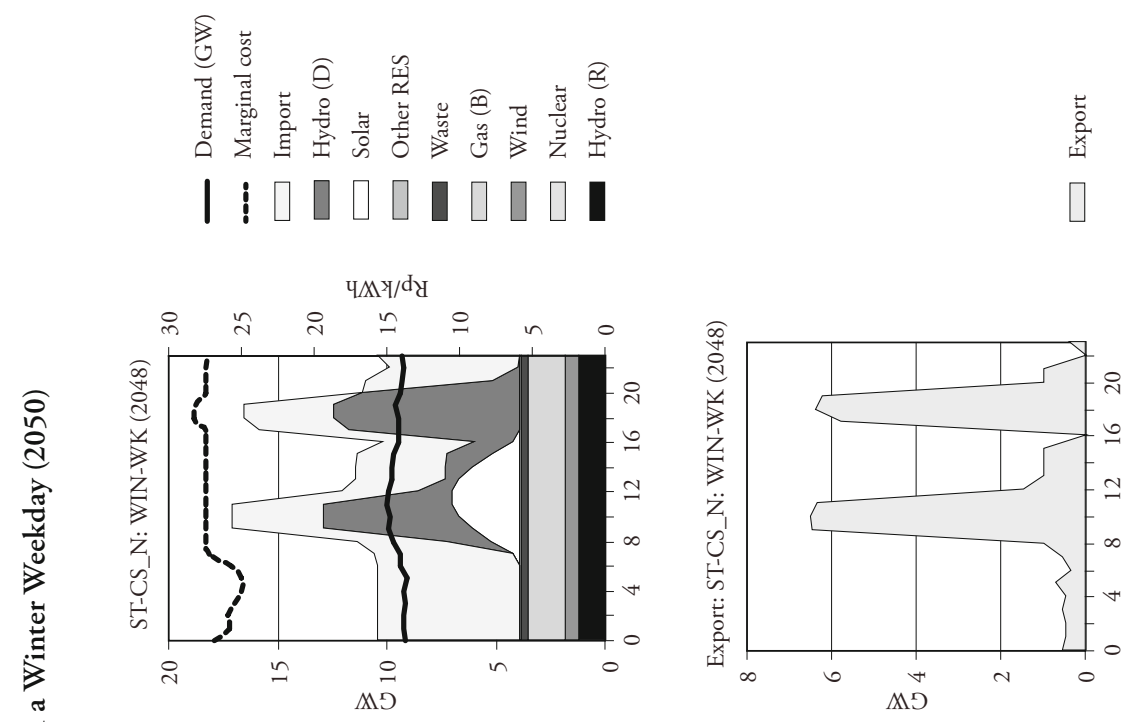

0ี
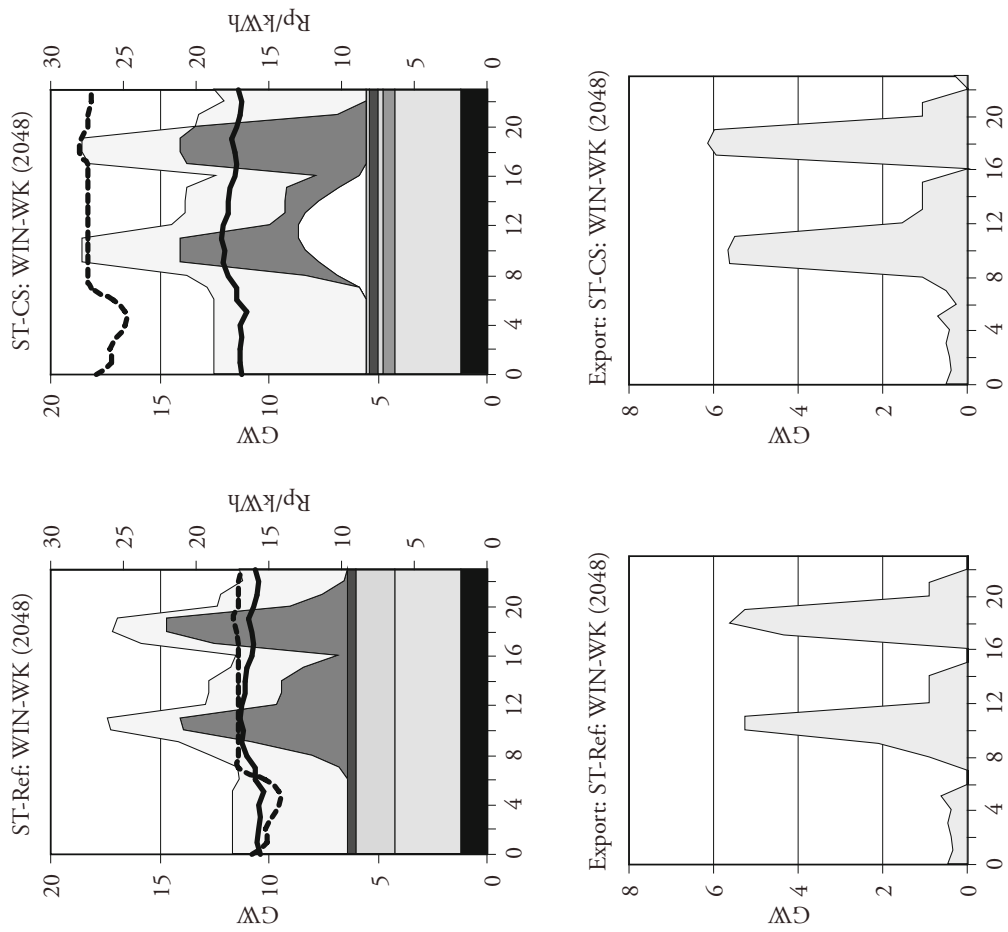

Swiss Journal of Economics and Statistics, 2012, Vol. 148 (2) 


\section{Comparison of Two Modelling Approaches}

Since the scope of the two modelling approaches differs, we have compared some key tradeoffs in the electricity sector in both modelling approaches.

\subsection{Technology Choice}

Optimisation of the electricity generation mix from both modelling approaches is consistent, even though some minor differences can be seen. For example, there is a relatively high uptake of renewable electricity generation, particularly biomassbased CHP (Figure 8) in the SMM model. This is because SMM accounts for the use of heat from CHP in end-use sectors (e.g. residential space heating) whereas the heat is unused in the electricity-only ST model, making CHP less attractive. Similarly, resource competition is lacking in the ST model which results in differences in carbon mitigation costs. For example, in both climate scenarios (CS and $C S \_N$ ), the ST model has a low marginal cost of $\mathrm{CO}_{2}$ (Figure 11b). This is partly because all biomass resources are available to the electricity sector in the ST model, whereas all sectors compete for the same biomass resource in SMM (e.g. residential and service for heating, transport for biofuel, and the power sector for electricity).

In the Ref scenario, the early uptake of solar PV with SMM occurs partly because of the highly aggregated representation of seasonal and diurnal variations in electricity output in this model. As a consequence, both solar PV output and demand are implicitly assumed to be more uniform in SMM (and thus well matched), whereas the ST model accounts for more variability and chooses gasfired plants to cope with higher winter demand (Figure $9 \&$ Figure 10). Consequently, solar PV is chosen for daytime demand and export markets in the later period in the ST model. Similarly, the uptake of hydro is slightly higher in the ST model than in SMM because dam hydro serves as reserve margin as well and an export-oriented electricity generation technology.

In general, the detailed depiction of the load curve and some aspects of trade in the ST model provide richer insights on dynamic supply and electricity trade benefits, which is not possible in the SMM model due to the aggregation of the electricity load curve. Given that Switzerland is a major exporter of electricity to neighbouring countries for peak demand due to its large dam and pumped hydro facilities, the developments in neighbouring markets are very crucial for the future of the Swiss electricity system. 


\subsection{Cost Implications}

It is not straightforward to compare the system costs of the two modelling approaches because of the differences in the scope, i.e. energy system vs. electricity sector only. Nevertheless, we estimated the undiscounted cost of the electricity sector from SMM to compare with the ST model (from which we must exclude the cost of interconnectors, and revenue from electricity trade (which are shown separately as 'others' in Figure 11)).

The resource cost for both models reflects the electricity generation mix the high resource cost in the climate ( $C S$ and $C S \_N$ ) scenarios of SMM can be attributed to the use of expensive biomass for CHP (as discussed in Section 6.1). At the same time, the high resource cost in the Ref scenario of the ST model is due to gas use.

The capital cost in the Ref scenario of the SMM model is high due to investments in capital-intensive solar PV, whereas the ST model invests in cheap combined-cycle gas power plants. In general, electricity system cost in the sectoral modelling approach is modestly higher than in the full energy system model because it accounts in more detail for the dispatchability of generation technologies and must maintain additional reserves for instantaneous peak demands, which are only approximated in the SMM (and somewhat lower because of aggregation and averaging of the load curve in SMM).

The marginal cost of $\mathrm{CO}_{2}$ from SMM reflects the system-wide $\mathrm{CO}_{2}$ marginal cost, whereas the ST model only estimates the $\mathrm{CO}_{2}$ marginal cost of the electricity sector. The marginal cost in SMM is relatively high because decarbonising some of the end-use sectors is very difficult (and thus the electricity sector is not the marginal source of abatement in these scenarios). On the other hand, the $\mathrm{CO}_{2}$ marginal cost is high in the ST model results in 2025 because of high electricity demand and the need to invest in expensive zero-carbon technologies to decarbonise the electricity sector. In comparison, SMM chooses to invest in expensive CHPs, with some of the costs partly offset by savings in other enduse sectors. For example, heat from CHP is used for the residential heating and thereby investment in residential heating is avoided. 
Figure 11: Undiscounted Electricity System Costs and Marginal Cost of $\mathrm{CO}_{2}$
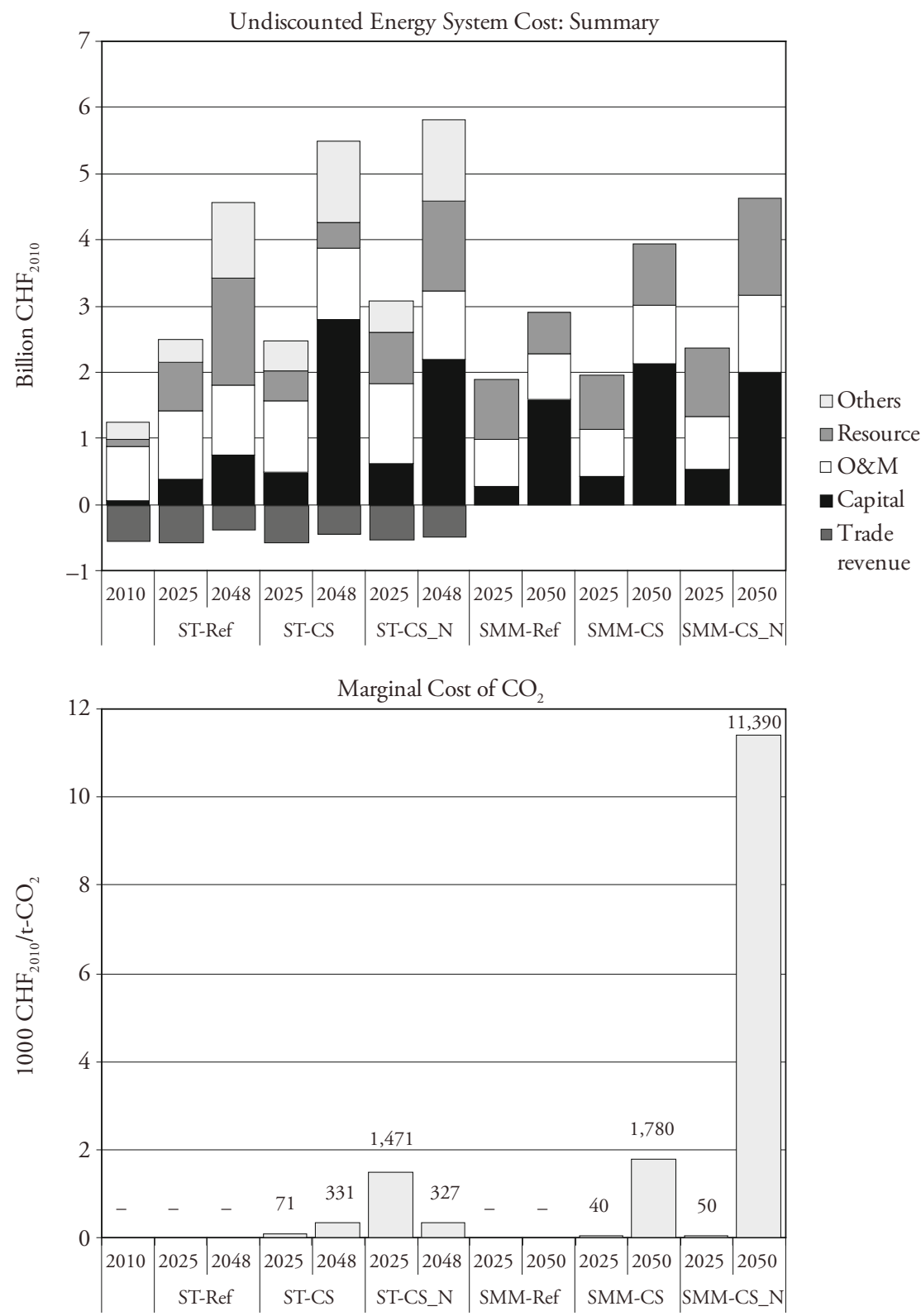


\section{Policy Implications}

In addition to comparing two complementary methodologies for long-term energy and electricity sector scenarios, this analysis has generated a number of insights in terms of energy policy options for Switzerland.

The results indicate that an ambitious climate policy target can be achieved, at a relatively small additional cost to the energy system. Realising such a target requires the implementation of abatement options across supply and demand sectors. Among these options, there is large scope to reduce emissions in transport and, in particular, the residential sector (which together account for two-thirds of total $\mathrm{CO}_{2}$ emissions today) through fuel switching from oil to gas or electricity. Moreover, many energy efficiency measures are cost effective across all scenarios, and should be exploited irrespective of some of the policy and other uncertainties facing Switzerland. However, there are likely to be market and information barriers which prevent the uptake of some of these efficient technologies, indicating the need for financial and regulatory incentives to accelerate the implementation of cost-effective demand-side efficiency measures.

A decision to phase out nuclear energy creates additional challenges, since it substantially raises the cost of decarbonising the electricity system (and thus reduces the attractiveness of fuel switching away from fossil fuels in end-use sectors). However, this challenge can be addressed technically with a combination of more aggressive efficiency measures, solar thermal heat systems, and accelerated deployment of renewables, particularly biomass-based CHP, which supports decarbonisation of end-use heat demand. This expansion of CHP will likely require additional investments for heat distribution systems in buildings, where there may be substantial barriers in the existing building stock (planning regulations, building codes, high costs). Regarding solar thermal, this technology is likely to compete for roof space with solar PV under a scenario with stringent abatement goals and a nuclear phase-out. Thus, further analysis is warranted of the relative economic advantages of these two options to make sure that market imperfections (e.g., consumer perceptions of PV vs. solar thermal) do not lead to a less efficient use of limited solar collection sites. For any techno-economic evaluation of technologies such as solar thermal or energy efficiency (e.g. for the payback period or life-cycle costing) the hourly marginal cost of electricity should be considered, rather than an average electricity cost (which would generally make these measures more attractive). It should also be mentioned that although many of the technology options deployed in the nuclear phase-out scenario may be more costly than nuclear generation, it seems likely that any possible future deployment of nuclear technology would face additional safety requirements and costs. 
Although from a technical perspective this analysis illustrates possible pathways for realising ambitious climate policy targets, the scale of the associated transition should not be underestimated. For instance, the levels of renewable energy deployment imply the installation of solar PV systems on all suitable rooftops, several large wind parks, and large-scale biomass production. The more detailed modelling of the electricity sector illustrates also that managing the resulting electricity mix will require a continuing integration and co-dependence of the Swiss electricity sector with the broader European electricity system. Further findings from the electricity dispatch schedule highlight the importance of providing a regulatory environment supportive of reinvestment in the existing hydro power capacity to maintain the low level of emissions in the power sector, as well as the flexibility to integrate other (intermittent) renewable sources. The flexibility of dam hydro facilities also contributes to the economic competitiveness of the electricity system, allowing Switzerland to benefit from imports of cheap night-time electricity while operating the hydro facilities during the day. At the same time, solar PV is also favourable to the high daytime demands as well as export. The large hydro capacity serves as reserve in any market conditions.

By identifying some of the technology elements needed to realise the climate and nuclear policy scenarios presented here, the analysis has also identified some potential threats. We can see that without access to secure imports of electricity to manage peak winter demands, major exploitation of energy efficiency options across all sectors, and extensive deployment of renewable energy, realising ambitious climate targets without nuclear energy may be prohibitively challenging. While the economic costs estimated here seem manageable, there may nonetheless be important barriers to a broad social and political acceptance of these requirements.

The analysis has also identified potential challenges over the very long term (beyond 2050), given the limited renewable potential in Switzerland. Continuing economic and potentially population growth will likely necessitate ongoing and aggressive measures to promote energy efficiency, particularly given that abatement targets are likely to become increasingly stringent. However, it should also be noted that the presented scenarios do not exhaust all the technological potential to reduce emissions. These scenarios have not considered, for example, an accelerated renovation of the building stock (instead, efficiency improvements occur in line with the historical renovation cycle); major changes to travel behaviour (car and air travel demand continue to grow); development of new large hydro sites; exploitation of geothermal energy; or adoption of carbon capture and storage technologies. Even if these options are avoided until 2050, some combination will likely be necessary beyond this timeframe given the need to further reduce emissions. 


\section{A Comparison with the 2050 Swiss Energy Strategy}

We compared our analyses discussed above with the 2050 Swiss Energy Strategy (SES) (BFE, 2011b) to provide additional insights into robust strategies and uncertainties associated with the long-term evolution of the Swiss energy system, and identify possible complementarities of the different methodologies. The SES presents two scenarios, namely Weiter Wie Bisher (WWB) (i.e. Business as usual) and Neue Energiepolitik (NEP) (i.e. New energy policy). The NEP scenario seeks to realize the 2000-Watt society by 2035 as analysed in the scenario IV of the Energieperspektiven 2035 (BFE, 2007). However, it is worth noting that both the $W W B$ and NEP assume the same macro-level of demand drivers, i.e. population, GDP, residential floor area.

Some differences arise between the two sets of scenarios because different methodologies have been applied in development and quantification. The scenarios presented in this paper were developed with SMM, a least-cost optimization modelling framework (see Section 2.1) which determines the combination of technologies and fuels to meet a given energy service demand. Our understanding from the associated preliminary documentation (BFE, 2011b) is that technology deployment in the SES scenarios is based primarily on expert judgement. In addition to the differences in the analytical approach, there are differences in the discount rate assumed $\left(2.5 \%\right.$ for the SES scenarios ${ }^{13}$ and $3 \%$ for SMM scenarios $^{14}$ ) and in key demand drivers (see Table 4): notably, higher population and economic growth in the SES scenarios. In addition, there are likely differences in assumptions about technology characteristics, although these are generally not reported in the SES documentation (BFE, 2011b). ${ }^{15}$ Given these differences in input assumptions and model framework, a systematic comparison between our and the SES scenarios is rather difficult, but some key outputs of the two analyses can be compared and brought in context with the assumptions. We compare below the $W W B$ scenario with our Ref scenario while the NEP is compared with the $C S$ scenario.

13 And 7\% for one electricity supply variant (BFE, 2011b, p. 116).

14 A decrease in social discount rate from $3 \%$ to $2.5 \%$ for the electricity generation technologies modelled in SMM and the ST model would reduce levelized costs by $5 \%$ (nuclear) and by 7-8\% (solar PV), and less for less capital-intensive technologies. Such a change in discount rate is not expected to have a significant impact on the scenario quantification presented here.

15 One important exception is nuclear generation costs (Prognos, 2011). Investment costs, fuel costs (incl. waste disposal), and operational characteristics are very similar to those in Table 1. Operation and maintenance costs in Table 1 are in the lower range of the literature reviewed in Prognos (2011), but do not significantly influence the results presented in this paper. 
Table 4: Scenario Assumptions SMM vs. SES

\begin{tabular}{|c|c|c|c|}
\hline & SMM & SES & Remarks \\
\hline $\begin{array}{l}\text { Analytical } \\
\text { framework }\end{array}$ & $\begin{array}{l}\text { Least cost optimization } \\
\text { model }\end{array}$ & $\begin{array}{l}\text { Descriptive storyline } \\
\text { scenario approach }\end{array}$ & \\
\hline Discount rate & $3 \%$ & $2.5 \%$ & \\
\hline GDP & $\begin{array}{l}30 \% \text { increase from } \\
2010 \text { level }\end{array}$ & $\begin{array}{l}50 \% \text { increase from } \\
2009 \text { level }\end{array}$ & \\
\hline Population & $\begin{array}{l}9 \% \text { decline from } 2009 \\
\text { (From } 7.3 \text { million } \\
\text { (2000) to } 7.4 \text { million } \\
\text { in } 2030 \text { and } 7.2 \text { million } \\
\text { by } 2050\end{array}$ & $\begin{array}{l}\text { A } 16 \% \text { increase from } \\
2009 \text { ( } 9 \text { million by } \\
2050)\end{array}$ & $\begin{array}{l}\text { The SMM assumption } \\
\text { is based on Schulz } \\
\text { (2007) }\end{array}$ \\
\hline $\begin{array}{l}\text { Residential floor } \\
\text { area }\end{array}$ & $\begin{array}{l}30 \% \text { increase from } \\
2009\end{array}$ & $\begin{array}{l}40 \% \text { increase from } \\
2009\end{array}$ & \\
\hline Oil price in 2050 & $145 \mathrm{US}_{2009} / \mathrm{bbl}$ & $\begin{array}{l}\text { WWB: } 116 \text { US }_{2009} / \mathrm{bbl} \\
N E P: 83 \mathrm{US}_{2009} / \mathrm{bbl}\end{array}$ & \\
\hline $\begin{array}{l}\text { General energy } \\
\text { prices }\end{array}$ & $\begin{array}{l}\text { Uniform energy prices } \\
\text { across the energy sectors }\end{array}$ & $\begin{array}{l}\text { Sector specific energy } \\
\text { prices }\end{array}$ & \\
\hline Carbon price & $\begin{array}{l}\text { No explicit carbon } \\
\text { price, instead carbon } \\
\text { cap is imposed (section } \\
\text { 3.2). No carbon cap in } \\
\text { Ref scenario. }\end{array}$ & $\begin{array}{l}\text { Explicit carbon price -> } \\
56 \mathrm{US} \$ 2009 / \mathrm{t} \text { in } 2050 \\
\text { for WWB and } 137 \\
\mathrm{US} \$ 2009 / \mathrm{t} \text { in } 2050 \text { for } \\
N E P\end{array}$ & $\begin{array}{l}\text { It is unclear how the } \\
\text { carbon prices are } \\
\text { applied to different } \\
\text { sectors in the SES. } \\
\text { Note: } C S \text { and } N E P \\
\text { scenarios appear to } \\
\text { have a similar level of } \\
\text { domestic emissions } \\
\text { (i.e., excl. international } \\
\text { travel) in } 2050 \text {. }\end{array}$ \\
\hline Conservation & $\begin{array}{l}\text { A limited set of } \\
\text { building conservation } \\
\text { with cost details }\end{array}$ & $\begin{array}{l}\text { A range of technical } \\
\text { conservation without } \\
\text { any cost }\end{array}$ & \\
\hline
\end{tabular}

Figure 12 shows final energy demand by end-use sector and fuel from both analyses. For the year 2009, we have also included the actual final energy data in Figure 12 from $\mathrm{BFE}$ (2010a). It is worth noting that SMM is calibrated to energy data from the BFE for 2000-2009 (BFE, 2000; 2010a; 2010b). However, total final energy demand in 2010 from SMM is $2 \%$ lower than actual final energy data partially because sufficient data were not available to fully calibrate all 
technology options and the building stock to 2009 (which are instead calibrated to earlier years); and because in SMM 2010 represents an average of the period 2008-2012. In the SES scenarios, final energy demand in 2009 is about $5.4 \%$ (i.e. 47 PJ) lower than actual final energy data published in BFE (2010a). The difference is particularly seen in the transport sector and oil demand, and it appears likely that the SES analysis considers only fuel used for domestic transport.

After accounting for the discrepancy in 2009, in later periods final energy demand of the $W W B$ scenario tends to be slightly higher than in the SMM Ref scenario. This is consistent with the higher population and GDP assumptions for the SES scenarios. That is, the change in energy intensity per unit of GDP appears to be very similar in the two scenarios (after accounting for the discrepancy in 2009).

Although total final energy demand and energy intensity are similar, there are differences in sectoral energy use and fuel mix (Figure 12). For example, in 2050, energy demand in the transport sector in the Refscenario is around $120 \mathrm{PJ}$ higher than in the $W W B$ scenario, whereas the residential energy demand is 54 PJ lower. Setting aside the differences in 2009, the lower transport fuel demand in the $W W B$ scenarios is due to the high penetration of electric cars assumed in this scenario $(\mathrm{BFE} 2011 \mathrm{~b}, \mathrm{p} .12)$. In comparison, hardly any electric cars are seen in our Refscenario (see Figure 5) because this technology is not cost-effective due to assumed high capital costs relative to conventional cars; and low energy prices without stringent $\mathrm{CO}_{2}$ policy. ${ }^{16}$ The uptake of electric cars in the $W W B$ scenario reduces oil demand and increases electricity demand (see Figure 12). In the residential sector, final energy demand is lower in the Refscenario than in the WWB scenario mainly due to the deployment of energy-saving options which are costeffective with the increasing energy prices in the scenario. Although the increase in oil prices is similar in $W W B$, this scenario does not appear to incorporate as significant energy saving. In terms of fuel mix, in the Refscenario natural gas is used to a greater extent than in WWB, where oil and electricity play a larger role.

Unlike the Ref and WWB scenarios, the CS and NEP scenarios exhibit much larger differences in final energy demand, with final energy demand in the $C S$ scenario $42 \%$ higher than in the NEP scenario in 2050 (see Figure 13). This is

16 The future cost of different technology options is a key uncertainty for the future development of the energy system. Thus, the divergence between transport sector energy use in the Refand WWB scenarios could in some way reflect different possible technology development outcomes, in addition to the differences in carbon price (Table 4) and the additional transport measures assumed in WWB (notably, passenger vehicle emission standards ( $130 \mathrm{~g} \mathrm{CO}_{2} /$ $\mathrm{km}$ from 2017 and $95 \mathrm{~g} \mathrm{CO}_{2} / \mathrm{km}$ from 2025). (BFE 2011b, p. 12). 
Figure 12: Comparison between SMM and Swiss Energy Strategy 2050 (Scenarios WWB vs. Ref)
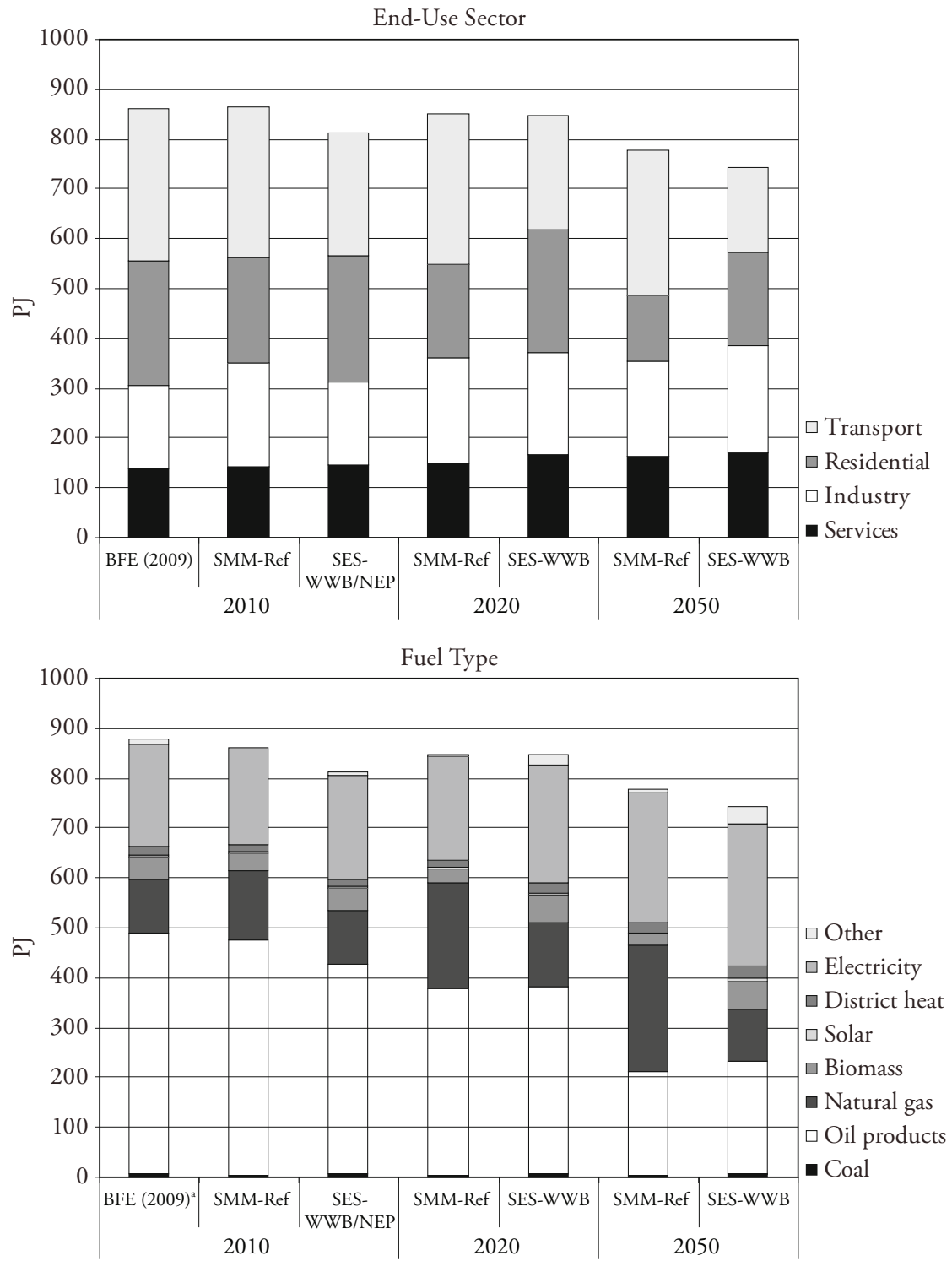

a The BFE (2009) value for total final energy by sector is lower than final energy demand by fuel since agricultural final energy is included in the latter. 
despite the NEP scenario incorporating the same macro-level drivers as in the $W W B$ scenario, i.e. GDP, population and residential floor area. The low energy demand in $N E P$ is assumed to be realised by undertaking extensive energy efficiency measures in end-use sectors, e.g. a complete switch to heat pumps for heating, electric cars, LED lighting, and so on (BFE, 2011b, p. 48). In comparison, not all of these options are assumed to be available in the SMM, and in SMM only cost-effective options are deployed. It is also worth noting that SMM assumes only a very limited number of energy saving technology options in the industrial sector. The largest differences between the NEP and CS scenarios occur in the transport sector (see Figure 13), where a large deployment of electric vehicles is assumed in $N E P$. In the $C S$ scenario, road transport uses primarily diesel and natural gas (see Figure 5).

In other end-use sectors the differences in final energy between $N E P$ and $C S$ are rather small. Despite the electrification in road transport in the NEP scenario, total electricity demand is slightly decreasing between 2020 and 2050 partially due to efficiency improvements in the services and industrial sectors. In contrast, in our $C S$ scenario total electricity demand increases; although there is substantial deployment of efficient appliances and energy saving options in this scenario, it is less extensive than assumed in $N E P$, as mentioned above.

In the context of electricity demand and electrification, it is worth highlighting an important methodological difference between the approach in this paper and in the SES scenarios. As discussed in Section 6, SMM depicts the entire Swiss energy system including energy supply and end-use demand. With this integrated system-wide structure SMM is able to offer insights into trade-offs between different sectors. For example, SMM can identify how a different choice of electricity generation technologies affects the choice of technology and energy carriers in the end-use sectors (e.g., if electricity is more expensive, efficiency and fuel switching become attractive in end-use sectors). In contrast, the electricity supply variants in SES are analysed independently of the energy system, so the scenario methodology does not appear to represent the influence of technology choice in the electricity sector on the rest of the energy system. For instance, the SES analyzes a number of electricity supply variants for $W W B$ and $N E P$, with different generation costs, but the documentation does not describe how these scenarios account for the impact of these different costs on the rest of the energy system. This leads to some somewhat counter-intuitive results, such as scenarios with a phase-out of nuclear generation where electricity costs are high, but in which there is a high penetration of electric vehicles.

In terms of electricity demand, the $W W B$ scenario shows a higher demand than our Ref scenario, whereas the electricity demand is lower in NEP than in 
Figure 13: Comparison between SMM and Swiss Energy Strategy 2050 (Scenarios NEP vs. CS)
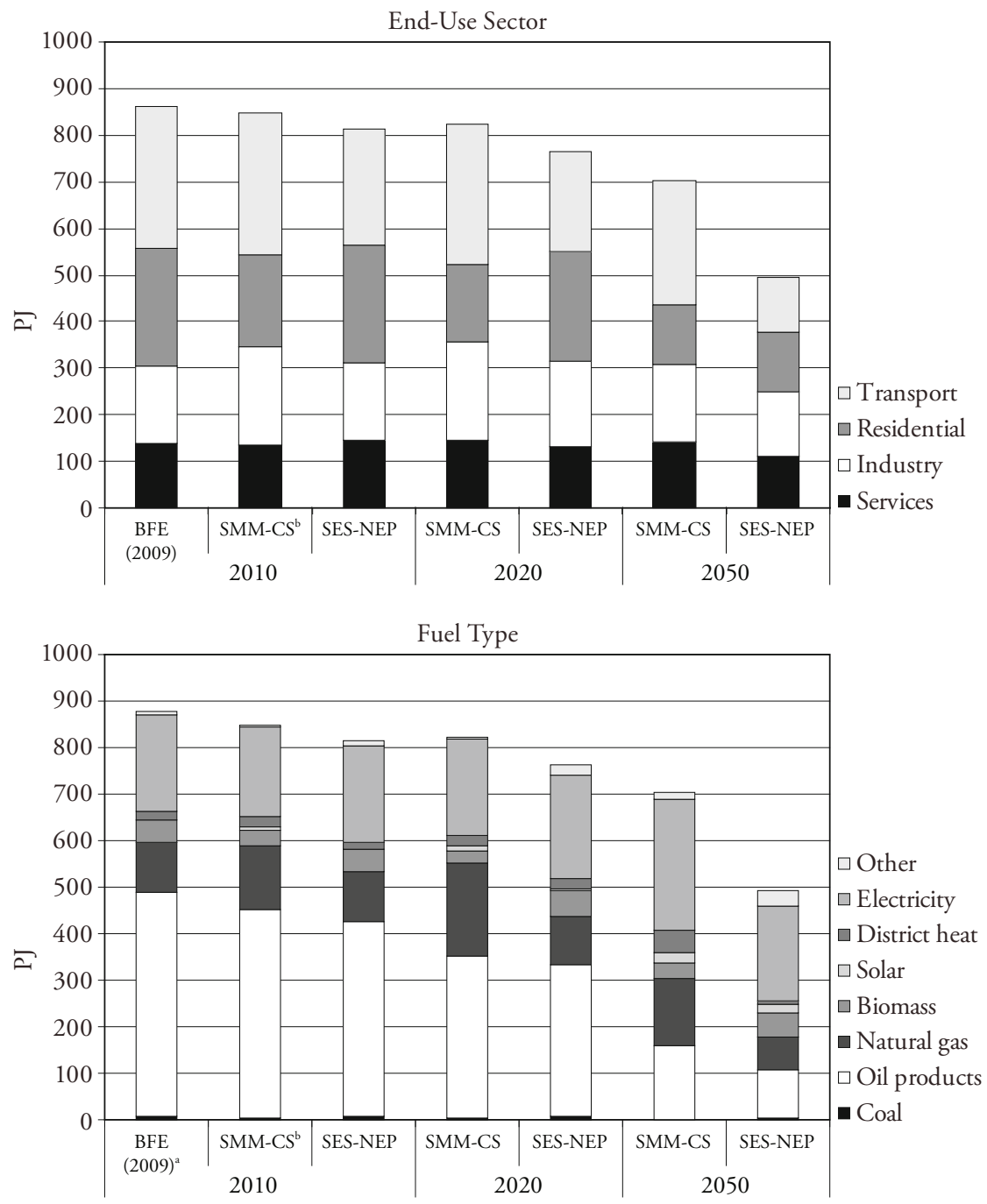

a The BFE (2009) value for total final energy by sector is lower than final energy demand by fuel since agricultural final energy is included in the latter.

b Final energy demand in 2010 for SMM-CS scenario is different from the SMM-Ref scenario since sufficient data were not available to fully calibrate the whole model to the year 2010 (some parts of the model are instead calibrated to earlier years). 
the $C S$ scenario. In our Ref and $C S$ scenarios, nuclear generation is limited to a maximum output equal to today's level, which is comparable to the WWB Bundesratsvariante 1 Variante $B$ scenario $^{17}$ in which nuclear contributes to $127 \mathrm{PJ}$ in 2050 versus $94 \mathrm{PJ}$ in our analysis. The higher electricity demand in 2050 in the WWB scenario of 285 PJ compared to our Refscenario (259 PJ) (Figure 12) coincides with higher nuclear and gas generation (127 and 41 PJ, versus 94 and 7 PJ, respectively)). However, renewable-based generation is higher in our Refscenario (for the reasons outlined in Section 4.1). In the case of the no-nuclear electricity scenarios, the generation mix is similar in our analysis and SES, though the SES scenarios have a higher share of renewable electricity. This may occur because the SES study assumes higher renewable energy potentials than applied in our analysis. For example, we did not include geothermal energy due to a range of uncertainties, whereas in the SES scenarios geothermal-based electricity plays a significant role.

\section{Conclusions and Outlook}

The primary advantage of energy system modelling approaches is in generating insights into cross-sectoral implications of future energy policies and technology choices. However, given the size of an energy system, computational limits in modelling sometimes result in a trade-off between covering the breadth of the energy system and representing sectors in depth (Kannan, 2009). This is illustrated in the analysis here where, for instance, we see that a more detailed sectoral approach in the ST model provides a richer characterisation of supply and demand technologies and the dynamics of the load curve. On the other hand, without the full energy system in a model such as SMM, implications related to cross-sectoral fuel substitution (e.g. electricity for transport, combined heat and power production), resource competition (e.g. biomass) and emission mitigation choice among sectors are ignored. Complementary modelling as presented here represents one way to overcome the limitations of each approach. A further step could be to incorporate both approaches in one model, despite challenges related to computational limits, data availability, understanding the model outputs, etc. (e.g. see Kannan, 2011). This is likely to require again compromises in sectoral depth, although there may be scope to incorporate additional key sectoral elements in energy system models without undermining their capabilities.

17 Bundesratsvariante 1 Variante B (Nuklear und fossil-zentral) is one of the five electricity supply scenarios reported for the given electricity demand from the $W W B$ scenario. 
The analysis of the electricity sector in this paper also illustrates that the generation schedule depends not only on seasonal/diurnal variation in the domestic demand, but is also strongly affected by assumptions on export and import prices in neighbouring markets. However, it is not possible to model the trade in a single region model without the details of cross-boarding countries' demand, supply and climate polices. This represents an area warranting further model development to improve analysis of electricity and energy system scenarios in a small interconnected electricity market such as Switzerland. In addition, it should be noted we have applied an exogenous scenario of energy service demand (although we account for energy saving options, and end-use efficiency). In reality, one would expect some of the energy system developments outlined in the scenarios above to affect energy service demand through behavioural and structural economic changes. Thus, linking the approaches in this analysis with complementary economic (i.e., top-down) modelling represents another area warranting further investigation.

\section{References}

ADAM - Adaptation and Mitigation Strategies: Supporting European climate policy" (2010), <http://www.adamproject.eu/>.

$\mathrm{BFE}$ - Bundesamt für Energie (2010a), „Schweizerische Gesamtenergiestatistik" (2000-2010), Bern. <http://www.bfe.admin.ch/themen/00526/00541/ 00542/00631/index.html?lang=de\&dossier_id=00763>.

$\mathrm{BFE}$ - Bundesamt für Energie (2010b), „Gesamte Erzeugung und Abgabe

Elektrischer Energie in der Schweiz" (2000-2010), Bern. <http://www. bfe.admin.ch/themen/00526/00541/00542/00630/index.html?lang=de\& dossier_id=00765>.

BFE - Bundesamt für Energie (2004), „Ausbaupotential der Wasserkraft“, Bern. BFE - Bundesamt für Energie (2007), „Die Energieperspektiven 2035“, Bern.

$\mathrm{BFE}$ - Bundesamt für Energie (2011a), „Medienmitteilung: Bundesrat beschliesst im Rahmen der neuen Energiestrategie schrittweisen Ausstieg aus der Kernenergie“, Bern, 25.05.2011.

BFE - Bundesamt für Energie (2011b), „Grundlagen für die Energiestrategie des

Bundesrates"; Frühjahr 2011 http://www.bfe.admin.ch/php/modules/publikationen/stream.php?extlang=de\&name=de_830045657.pdf.

$\mathrm{BFS}$ - Bundesamt für Statistik (2001), „Bevölkerungsentwicklung der Schweiz“,

DEMOS: Informationen aud der Demografie No 1+2/2001, Neuchâtel. 
ENTSOE - "European Network of Transmission System Operators for Electricity" (2010), https://www.entsoe.eu/index.php?id=55.

ETS - Der Energie Trialog Schweiz (2009), „Energie-Strategie 2050 - Impulse für die schweizerische Energiepolitik". Grundlagenbericht, <http://www.energietrialog.ch/cm_data/Grundlagenbericht.pdf>.

Häring, M. O., F. Lander, U. Schanz and T. Spillmann (2009), "Deep Heat Mining Basel - Preliminary Results". <http://www.geothermal.ch/fileadmin/ docs/downloads/dhm_egc300507.pdf>.

Hirschberg, S., R. Dones, T. Heck, P. Burgherr, W. Schenler, and C. Bauer (2004), "Sustainability of Electricity Supply Technologies under German Conditions: A Comparative Evaluation”. PSI-Report No.04-15. Paul Scherrer Institut, Villigen PSI, Switzerland.

IEA - International Energy Agency (2009), Word Energy Outlook.

JRC - Joint Research Centre (2009), Photovoltaic Geographical Information System (PVGIS): Geographical Assessment of Solar Resource and Performance of Photovoltaic Technology, <http://re.jrc.ec.europa.eu/pvgis/apps4/ pvest.php> [September 2009].

Kannan, R. (2009), "Uncertainties in Key Low Carbon Power Generation Technologies - Implication for UK Decarbonisation Targets", Applied Energy 86 (10): 1873-1886.

Kannan, R. (2011), "The Development and Application of a Temporal MARKAL Energy System Model Using Flexible Time Slicing”, Applied Energy 88 (6):2261-2272.

Kannan, R., and Turton H. (2011), "Documentation on the Development of Swiss TIMES Electricity Model (STEM-E)”, Paul Scherrer Institut, Switzerland.

LABriet, M. (2003), "Switzerland MARKAL Structure and Assumptions", Technical Report (not published), 2.0. Geneva: University of Geneva (LOGILAB), 2003.

Loulou, R., U. Remme, A. Kanudia, A. Lehtila, and G. Goldstein (2005), "Documentation for the TIMES Model", Energy Technology Systems Analysis Programme. <http://www.etsap.org/Docs/TIMESDoc-Intro.pdf>.

Marcucci, A.,Turton, H., (2011), "Swiss Energy Strategies under Global Climate Change and Nuclear Policy Uncertainty". Swiss Journal of Economics and Statistics, vol. 148(2), pp.317-345.

OcCC - The Advisory Body on Climate Change (2007), Medieninformation: OcCC-Stellungsnahme zur Ausgestaltung der „Schweizerischen Klimapolitik post 2012“, Bern [24.8.2007]. 
Odenberger, M., and T. Unger (2011), "The Role of New Interconnectors in European Energy Pathways: Pathways to Sustainable European Energy System", in F. Johnsonn (2011) Methods and Models used in the project used in the project Pathways to Sustainable European Energy Systems), Alliance for Global Sustainability. <http://www.energy-pathways.org/pdf/Metod_reportJan2011.pdf>.

Prognos (2011), „Kosten neuer Kernkraftwerke“, Basel, February.

PSI - Paul Scherrer Institut (2010), „Energie-Spiegel“, No.20,. <http://www.psi. ch/media/aktuelles-energiespiegel-nr_20>.

SAAS - Swiss Acadaemies of Arts and Sciences (2009), Stellungnahme: Vernehmlassung zur Revision CO2-Gesetz: Antwort der Akademien Schweiz. Bern, 17.3.2009.

SATW - Swiss Academy of Engineering Sciences (2007), "Road Map-Renewable Energies Switzerland: An analysis with a view to harnessing existing potentials by 2050 ".

Sceia, A., Altamirano-Cabrera, J.-C., Vielle, M., Weidmann, N., (2009), "Assessment of Acceptable Swiss post-2012 Climate Policies with a Hybrid Model", NCCR-Climate Working Paper 2009/04.

Schulz, T. F. (2007), "Intermediate Steps to the 2000 Watt Society in Switzerland: An Energy-Economic Scenario Analysis". DISS ETH NO 17314, ETH Zürich, 2007.

Schulz, T. F., Barreto, L., Kypreoos, S., Stucki, S., (2007), "Assessing WoodBased Synthetic Natural Gas Technologies Using the SWISS-MARKAL Model”. Energy 32 (10): 1948-1959.

Schulz, T. F., Kypreos, S., Barreto, L., Wokaun, A. (2008), "Intermediate Steps Towards a 2000 Watt Society in Switzerland: An Energy-Economic Scenario Analysis". Energy Policy 36 (4):1303-1317.

SNB - Swiss National Bank (2010), Historical Time Series 4: Interest Rates and Yields, Table 2.1 Money Market Rates, in CHF. <http://www.snb.ch/en/ iabout/stat/statpub/histz/id/statpub_histz_actual> [10 August 2010].

Swiss GRID (2008), Informationsveranstaltung Bilanzgruppenmanagement, $<$ http://www.swissgrid.ch/company/downloads/document/S080622_BGVinformation-event-balance-group-management.pdf/de>.

Weidmann, N., Turton, H., Wokaun, A., (2009), "Case Studies of the Swiss Energy System - Sensitivity to Scenario Assumptions Assessed with the Swiss MARKAL Model”. Studie im Auftrag des Energie Trialog Schweiz. Paul Scherrer Institut, Villigen PSI, Switzerland <www.energietrialog.ch>.

Wind-Data.CH (2010), Die Website für Windenergie-Daten der Schweiz: SwissMetNet Stationen <http://www.wind-data.ch/messdaten/list.php?field=ff50 $\&$ dir=ASC \&wmo=67350\&typ=perm $>$ (28 June 2010). 


\section{SUMMARY}

Decisions on climate change and nuclear policies are likely to have major influences on the future evolution of the Swiss energy system. To understand the implications of selected future policy decisions, we analyse the development of the Swiss energy system with a bottom-up technology-rich least-cost optimisation modelling framework. We use the Swiss MARKAL energy system model and analyse a stringent climate change mitigation policy with two policy variants on the availability of nuclear energy, i.e. with and without nuclear new builds. The energy system modelling approach provides insights into system-wide energy pathways, technology choice and cross-sectoral trade-offs like resource competition, electrification, and $\mathrm{CO}_{2}$ mitigation options across supply and demand sectors. To complement the full system approach, we apply an experimental TIMES model - a successor to MARKAL - of the Swiss electricity sector with a detailed representation of the electricity load curve accounting for diurnal and seasonal variations in demand and resource supply. The analytical results from both modelling approaches are presented and the electricity sector results compared to illustrate the complementary policy insights. The implications for realising an ambitious climate target with and without investment in new nuclear plants are discussed, and a number of areas for possible policy support identified. 